\title{
Supermolecules as Medicinal Drugs
}

\author{
Cheng-He Zhou and Yan-Fei Sui
}

\section{Contents}

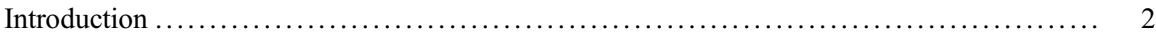

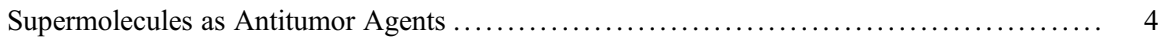

Macrocycle-Based Supermolecules as Antitumor Agents ........................ 4

Metal-Based Supermolecules as Antitumor Agents ............................... 8

Polymer-Based Supermolecules as Antitumor Agents ........................... 12

Supermolecules as Antiinflammatory and Analgesic Agents .......................... 14

Supermolecules as Antimalarial Agents ........................................ 16

Supermolecules as Antibacterial Agents ....................................... 17

Quinolone-Based Supermolecules as Antibacterial Agents ....................... 17

Sulfanilamide-Based Supermolecules as Antibacterial Agents ...................... 19

Schiff Base-Based Supermolecules as Antibacterial Agents ........................ 20

Hydrazone-Based Supermolecules as Antibacterial Agents ........................ 21

Thiosemicarbazone-Based Supermolecules as Antibacterial Agents ................. 22

Macrocycle-Based Supermolecules as Antibacterial Agents ....................... 24

Other Supermolecules as Antibacterial Agents .............................. 25

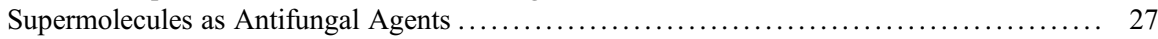

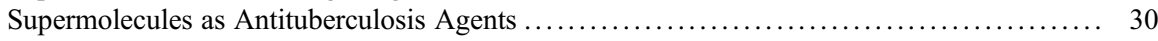

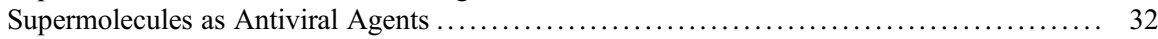

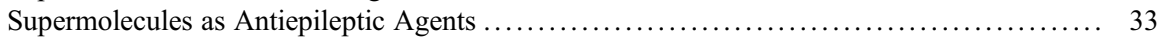

Supermolecules as Cardiovascular Agents ..................................... 35

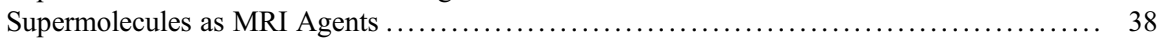

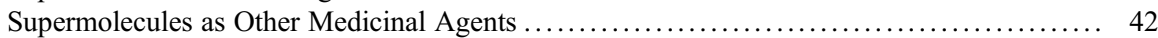

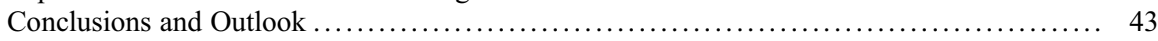

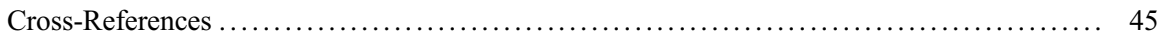

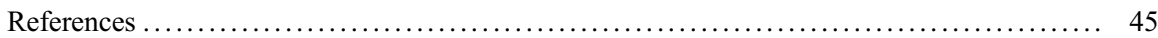

C.-H. Zhou $(\bowtie) \cdot$ Y.-F. Sui

Institute of Bioorganic \& Medicinal Chemistry, School of Chemistry and Chemical Engineering, Southwest University, Chongqing, China

e-mail: zhouch@swu.edu.cn; suiyf2018@email.swu.edu.cn 


\section{Introduction}

Supramolecular chemistry is a rapidly expansive scientific interdiscipline, strongly promoting the development of chemistry at a revolutionary pace [1-3]. Numerous efforts have been devoted to the study of supramolecular chemistry, which has been extended and developed in many disciplines such as materials science, biology, medicine, and pharmaceuticals [4-6]. Many outstanding achievements have been made [7-9]. Generally, supermolecules are described as aggregates formed by two or more molecules through noncovalent bonds. According to this definition, the inorganic and organic complexes could be attributed to supermolecules. The main driving force for the formation of inorganic complex supramolecular aggregates is coordination bonds, whereas the driving force for organic supramolecular aggregates is mainly hydrogen bonds, ionic bonds, and van der Waals forces. The inorganic complexes or aggregates formed by inorganic compounds or organic compounds can be regarded as inorganic supermolecules. The anticancer drug cisplatin is an example. This drug is usually considered to be the inorganic metal complex formed by one molecule of the inorganic compound $\mathrm{PtCl}_{2}$ and two $\mathrm{NH}_{3}$ molecules through coordination bonds; this complex is an aggregate of three molecules formed through noncovalent bonds (here generally considered to be coordination bonds). Therefore, cisplatin could be called an inorganic (complex) supermolecule. Similarly, the organic complexes or aggregates formed by organic compounds and organic compounds could be regarded as organic complexes or supermolecules. Considering the complex of $\beta$-cyclodextrin with the anticancer drug adriamycin, it was found that the organic molecule $\beta$-cyclodextrin, with another organic molecule, the anticancer adriamycin, in aqueous solution formed a 1:1 host-guest complex. The drug adriamycin is generally considered to enter into the cavity of macrocyclic cyclodextrin, often called an (organic) inclusion complex. This complex is an aggregate formed by one molecule of $\beta$-cyclodextrin and one molecule of adriamycin, mainly through noncovalent bond forces such as hydrophobic interaction or van der Waals forces. Thus, such a complex should be an organic supermolecule. Supermolecules or polymolecular assemblies formed by the weak interactions of noncovalent bonds via self-process, self-assembly, or self-organization show distinct chemical, physical, and biological properties in comparison with their precursor molecules. These supramolecular systems exhibit some specific functions, being capable of being used as conductors, magnetic materials, or sensors, and thus they have wide potential application in chemistry, physics, the medical sciences, and other fields [10-12].

It is well known that supermolecules have important roles in living biological systems. Chlorophyll in plant photosynthesis is the magnesium tetrapyrrole complex supermolecule, heme in hemoglobin in uptake and transport of oxygen is the iron complex supermolecule of porphyrin ring, and vitamin $\mathrm{B}_{12}$ is the cobalt macrocyclic complex supermolecule. Therefore, to some extent, the living biological system is a huge and particularly excellent biological supramolecular system in which the supramolecular hosts are various kinds of enzymes, receptors, genes, antibodies of 
the immune system, or ionophores, whereas the guests are substrates, inhibitors, antigens, drugs, and so on. The synergistic cooperation between hosts and guests supports biological processes in living biological systems. Utilization of interactions of noncovalent bonds, in attempts to study molecular recognition, regulation, and control, modeling or mimicking enzyme catalysis in biological processes, DNA binding, membrane transport, cell-cell recognition, as well as investigating drug interactions, has become an unusually active research area of supramolecular chemistry in the life sciences, providing a new approach for the development of new drugs. The highly interdisciplinary research in this field is considered to be an important source for new concepts with high technology. The noncovalent interactions in biological supramolecular systems should be highly useful for the development of supramolecular drugs. However, surprisingly, the word "supramolecular drug" has seldom been mentioned. The concept of supermolecular drugs, as described by Prof. Cheng-He Zhou early in 2009, defined that a supramolecular drug was formed by two or more molecules through noncovalent bonds [13, 14].

The wide extension and rapid development of supramolecular chemistry into scientific disciplines has attracted much exploration toward applying supramolecular systems in pharmaceutical sciences. Since the discovery of the inorganic platinum complex cisplatin as an anticancer agent, research for medicinal application of inorganic metal complex supermolecules has been active. The two inorganic compounds, $\mathrm{PtCl}_{2}$ and $\mathrm{NH}_{3}$, are not anticancer drugs, but their cisplatin complex formed through noncovalent bonds is used widely clinically as an anticancer drug. The anticancer drug cisplatin has thus opened up a new era for the research and development of new medicinal drugs, with numerous endeavors toward inorganic complex supermolecules as drugs formed by inorganic metal compounds with inorganic compounds such as $\mathrm{NH}_{3}$ or organic compounds such as diamines and porphyrins. In particular, supramolecular inclusion complexes, formed by organic macrocyclic compounds such as cyclodextrins and their derivatives as hosts with guest drugs, not only could improve the water solubility of original drugs, control drug release in the body, assist drug delivery to the target organ, or even eliminate abnormal flavors of drugs, but also effectively improve the pharmacokinetics properties of drugs, increasing their bioavailability and efficacy. These special advantages for drugs have encouraged and attracted numerous workers to engage in research and development of supramolecular drugs. Currently, research in supramolecular drugs is quite active and the progress unusually rapid, becoming an emerging highly interdisciplinary field with enormous potential and gradually becoming a relatively independent scientific area. To date, a large number of supermolecules as medicinal drugs have been widely used in clinics. Supermolecules as medicinal drugs show not only less expense, shorter time, and greater possibility as clinic drugs with their successful research and development, but also safety, lower toxicity, less adverse effect, higher bioavailability, better biocompatibility and drug targeting, less drug resistance, and better curative effects, exhibiting extensive potential for clinical use. This chapter provides a comprehensive summary of supramolecular drugs, 
including antitumor, antiinflammatory, analgesic, antimalarial, antibacterial, antifungal, antivirus, antiepileptic, and cardiovascular agents and agents for magnetic resonance imaging . The foreseeable perspectives for future development of supermolecules as medicinal drugs are also presented.

\section{Supermolecules as Antitumor Agents}

Cancer is a frequently occurring and formidable disease that seriously threatens human health. The development of anticancer drugs has become an important issue in the world. In recent years, various achievements have been obtained in seeking drugs and methods for treating cancers, such as apoptosis antileptics, signal conduction blockade agents, angiogenesis inhibitors, and chemotherapy and radiotherapy protectants. Supermolecules as anticancer drugs have become highlighted, especially cyclodextrin inclusion compounds, liposomes, nanometer particles, and metal complexes such as platinum, as representative supramolecular chemical drugs important in treating cancers $[15,16]$.

\section{Macrocycle-Based Supermolecules as Antitumor Agents}

Organic macrocyclic compounds are excellent hosts to form supermolecules. Macrocycles such as cyclodextrins (CDs), cyclophanes, crown ethers, calixarenes, porphyrins, phthalocyanines, cyclopeptides, and cucurbiturils, for example, provide rich host resources.

The CDs are a class of D-glucopyranose-based special macrocyclic hosts with a hydrophilic exterior and a hydrophobic cavity. These cavities with appropriate size enable them to form inclusion complex supermolecules with various hydrophobic drugs, resulting in improvement of the drug properties such as solubility, chemical stability, bioavailability, drug release control, or even elimination of abnormal drug flavor. Therefore, the CDs possess good application prospects in oral administration preparation, and they have also become important useful functional excipients in modern pharmaceuticals because of their features, such as being easy to obtain, better biocompatibility, almost no adverse effects, and stable chemical properties as well as clathration simplicity with guest drugs.

Cyclodextrin derivatives with different solubilities can meet the requirements of appropriate drug release. The extensively used cyclodextrins are $\beta-\mathrm{CD}$, especially its derivatives such as hydroxypropyl- $\beta$-CD (HP- $\beta$-CD), hydroxyethyl- $\beta$-CD (HE- $\beta$ $\mathrm{CD}$ ), and trimethyl- $\beta-\mathrm{CD}$ (TM- $\beta-\mathrm{CD})$. The $\beta-\mathrm{CD}$ with an appropriate cavity size and shape could bind efficiently with a series of hydrophobic aromatic guests, and also is widely investigated and applied because of its low price. For instance, anticancer drug doxorubicin 1 and $\beta$-CD could form a 1:1 inclusion complex. Prof. Yu Liu and coworkers found that this supermolecule remarkably improved the water solubility of doxorubicin and enhanced its efficacy as a drug. 


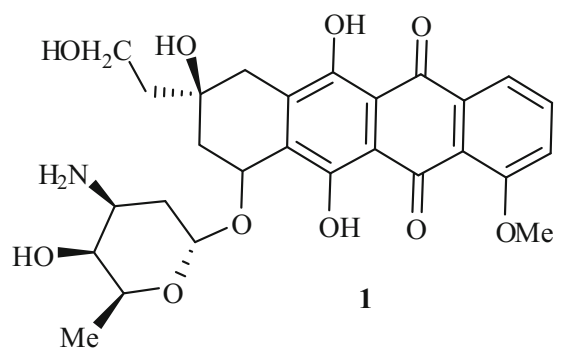

One highlight is to modify the structures of CDs in various ways to increase their drug-loading capability. Much work on the structural modifications of methylation, hydroxymethylation, sulfonylation, and sulfur alkylation is hoped to improve the water solubility and inclusion capability of $\beta$-CDs; some good results in enhancement of water solubility and the complexation capability of CDs have been obtained to different extents. The $\beta$-CD dimers and linear polymers could serve as potent selective carriers of drugs such as the anticancer agent busulfan, and improved the physicochemical properties of drugs. Prof. Liu Yu et al. used bis $(\beta-C D)$ s with paclitaxel to form inclusion complex supermolecules, hoping to improve the water solubility and antineoplastic activity of paclitaxel. Among these supermolecules, the complex of ethylenediamine-bridged $\beta-\mathrm{CD}$ dimer significantly increased the water solubility and thermal stability of paclitaxel, and exhibited antiproliferative activity against the human $\mathrm{K} 562$ erythroleukemia cell line $\left(\mathrm{IC}_{50}\right.$ value, $0.6 \mathrm{nmol} \cdot \mathrm{l}^{-1}$ ), which was even better than that of free paclitaxel $\left(\mathrm{IC}_{50}\right.$ value, $\left.0.98 \mathrm{nmol} \cdot 1^{-1}\right)$. The bridged $\mathrm{CD}$ could also greatly increase complexation ability to drugs by interactions of the drug molecule with two adjacent hydrophobic cavities.

Supramolecular nano-assemblies responding to multiple stimuli exhibit high therapeutic efficacy against malignant tumors. A new type of supramolecular nanofiber integrated targeting peptide 2 -coated magnetic nanoparticles with $\beta$-cyclodextrin-bearing polysaccharides in a complex held together by multivalent interactions. The nanofibers markedly suppressed invasion and metastasis of cancer cells both in vitro and in vivo. Furthermore, in comparison with control mice, tumor-burdened mice treated with the nanofiber assembly showed a lower rate of mortality from the metastatic spread of tumor cells [17].
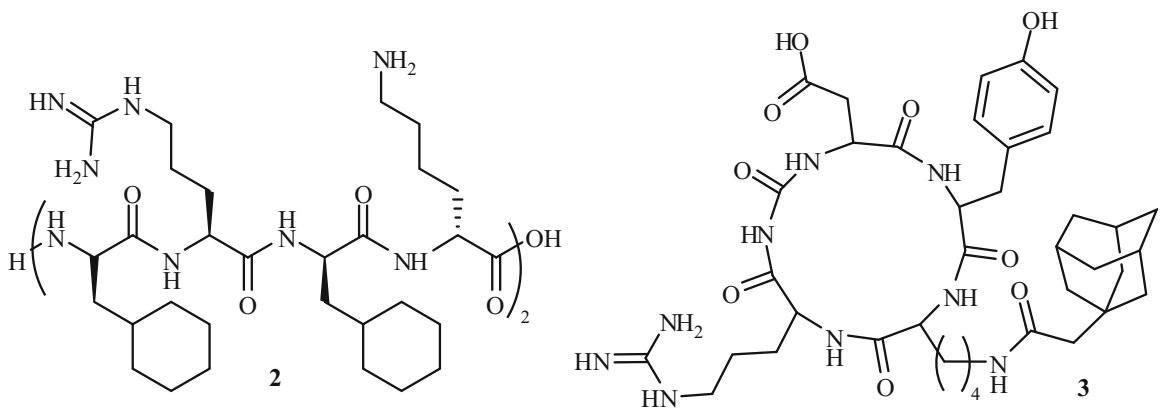
A recent study developed a $\beta$-CD-functionalized $\mathrm{Ru}(\mathrm{II})$ polypyridyl complex supermolecule with an adamantane-appended tumor-targeting $\mathrm{c}(\mathrm{RGDyK})$ peptide 3. The host-guest system can form stable phosphorescent nanostructures with quantitative drug loading. The formed nanoparticles, Ru-CD-RGD, displayed high selectivity for integrin $\alpha_{\mathrm{v}} \beta_{3}$-rich U87MG cancer cells as compared with integrin $\alpha_{v} \beta_{3}$-deficient cancer cells. Mechanistic studies showed that Ru-CD-RGD could induce apoptotic cell death through lysosomal damage, reactive oxygen species (ROS) elevation, and caspase activation [18].

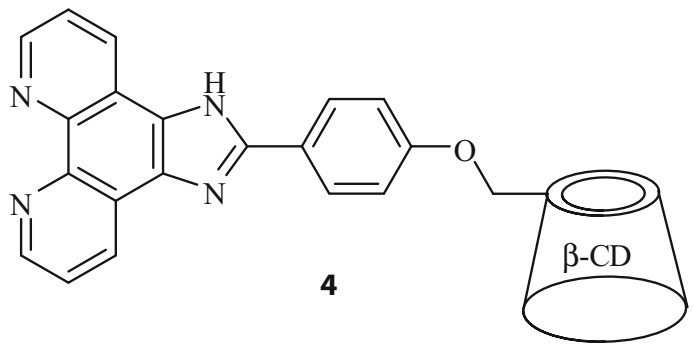

Supramolecular assembly with tumor-targeting properties or photodynamic therapy (PDT) ability has recently become a focus of interest in the biomaterial field because of its high therapeutic efficacy against tumor cells. A $\beta$-cyclodextrinfunctionalized compound $\mathbf{4}$ formed a ruthenium complex that acted as the targeted sites for tumor cells, the coordinated Ru (II) centers acted as the PDT-active sites, and the biocompatible polysaccharide $\beta$-cyclodextrins acted as the noncovalent linkers. Significantly, the resultant $\mathrm{Ru} /$ polysaccharide/protein complex exhibited not only specific targeting properties toward tumor cells but also high PDT ability under visible light irradiation. Furthermore, the assembly showed selective killing toward tumor cells combined with negligible toxicity toward normal cells [19].

The porphyrin ring possessed the structural features of both macrocycles and multidentes. Porphyrins and their metalloporphyrins may offer many distinct physicochemical properties and functions when changing substituents in the porphyrin ring, adjusting the electron-donor ability of four nitrogen atoms, introducing different center metal ions, or changing the affinity of axial ligands [20]. In recent years, PDT has become the fourth new and reliable treatment for cancer, after surgery, radiotherapy, and chemotherapy. Porphyrin-based anticancer drugs generally act as photosensitizers to generate photodynamic reactions when light at the appropriate wavelength is applied, give highly active oxygen singlets, and then destroy the target cells. The widely used drugs in the clinic are hematoporphyrin derivatives, the first generation of photosensitizers with high phototoxicity and dark toxicity. Recently, principal studies have been focusing on exploring new photosensitizers with singlet oxygen in high yields, with strong absorption at or near the infrared region, as well as better targeted intelligence carriers. 
Camptothecin (CPT) selectively traps topoisomerase 1-DNA cleavable complexes (Toplcc) to promote anticancer activity. A new class of neutral porphyrin derivative, 5,10-bis(4-carboxyphenyl)-15, 20-bis(4-dimethylaminophenyl)-porphyrin as a potent catalytic inhibitor of human Top1, was designed and synthesized. In contrast to CPT, compound 5 reversibly binds with the free enzyme, inhibits the formation of Toplcc, and promotes reversal of the preformed Toplcc with CPT. Compound 5-induced inhibition of Top1cc formation in live cells was substantiated by fluorescence recovery after photobleaching (FRAP) assays. The study established that MCF7 cells treated with compound 5 trigger proteasome-mediated Top1 degradation, accumulate higher levels of ROS, PARP1 cleavage, and oxidative DNA fragmentation, and stimulate apoptotic cell death without stabilizing apoptotic Top1-DNA cleavage complexes. Finally, compound 5 shows anticancer activity by targeting cellular Top 1 and preventing the enzyme from directly participating in the apoptotic process [21].

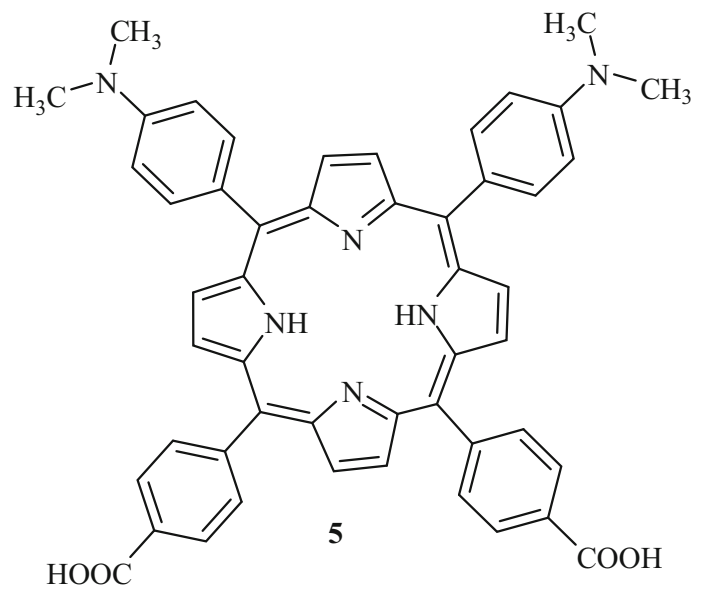

Identification of the molecular target(s) of anticancer metal complexes is a formidable challenge because most of them are unstable toward ligand-exchange reaction(s) or biological reduction under physiological conditions. Gold(III) tetraphenylporphyrin $\mathbf{6}$ is notable for its high stability in biological milieux and potent in vitro and in vivo anticancer activities. Herein, extensive chemical biology approaches employing photo-affinity labeling, click chemistry, chemical proteomics, cellular thermal shift, saturation-transfer difference, nuclear magnetic resonance imaging (NMR), protein fluorescence quenching, and protein chaperone assays were used to provide compelling evidence that heat-shock protein 60 (Hsp60), a mitochondrial chaperone and potential anticancer target, is a direct target of $\mathbf{6}$ in vitro and in cells. Structure-activity studies with a panel of non-porphyrin gold(III) complexes and other metalloporphyrins revealed that Hsp60 inhibition is specifically dependent on both the gold(III) ion and the porphyrin ligand [22]. 


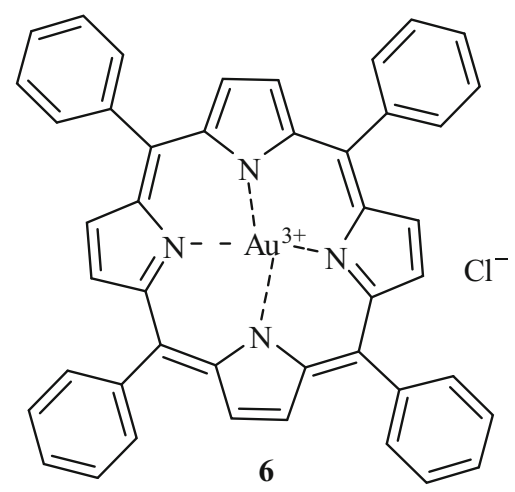

The bis-NHC complexes exhibited potent dark cytotoxicity toward a panel of cancer cells with IC50 values at submicromolar levels. The cytotoxicity of these complexes could be further enhanced upon light irradiation, with $\mathrm{IC}_{50}$ values as low as nanomolar levels in association with the light-induced generation of ROS. Bioimaging indicates that the Ir complex mainly targets the endoplasmic reticulum. It catalyzes the photoinduced generation of singlet oxygen and triggers protein oxidation, cell cycle arrest, apoptosis, and the inhibition of angiogenesis. It also causes pronounced photoinduced inhibition of tumor growth in a mouse model of human cancer [23].

Other macrocycles such as cyclophanes, calixarenes, and cucurbiturils as hosts to form supramolecular drugs were also extensively investigated.

\section{Metal-Based Supermolecules as Antitumor Agents}

Metal anticancer complexes are a vigorous research field. Noble metal-based complex supramolecular drugs especially have achieved great success. Many metal complex supramolecular drugs such as cisplatin and carboplatin have been widely used clinically. Numerous researchers have been encouraged to develop precious metals as anticancer drugs. Platinum complexes are widely used clinically. So far, fewer non-platinum metal anticancer drugs have been approved for cancer chemotherapy, but some metal complex supermolecules of ruthenium, titanium, or gallium have already been tested in clinical phases.

It is well known that a series of platinum complexes has been investigated extensively since the inorganic coordination complex of platinum, cisplatin, was found to exhibit antitumor activity in 1969. Cisplatin 7 as an anticancer drug was approved by the United States (USA) in 1978, and it is also widely used to treat many kinds of malignancies, including testicular, ovarian, cervical, and bladder types. The distinct anticancer mechanism, wide anticancer spectrum, and different toxicity spectrum of platinum complexes from many natural and nonnatural drugs, has focused more and more studies on platinum complexes. After cisplatin, several 
other platinum complexes such as carboplatin $\mathbf{8}$, nedaplatin $\mathbf{9}$, oxaliplatin $\mathbf{1 0}$, sunpla 11, and lobaplatin $\mathbf{1 2}$ have been approved for current tumor therapy.

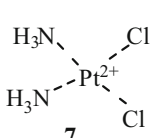<smiles>N[P+]1(N)OC(=O)C2(CCC2)C(=O)O1</smiles><smiles>O=C1O[P+]2(N[C@@H]3CCCC[C@H]3[NH2+]2)OC1=O</smiles><smiles>N[P+]1(N)OCC(=O)O1</smiles><smiles>CC(C)CC(=O)OC1CN[P+]2([Tl])NCC1OC(C(C)C)CO2</smiles><smiles>C[C@H]1O[P+]2(NC[C@H]3CC[C@@H]3CN2)OC1=O</smiles>

Although cisplatin and carboplatin are the first choice as anticancer drugs, they have side effects of nephrotoxicity, neurotoxicity, and poor targeting. Therefore, much research based on the structures of cisplatin and carboplatin, according to the classic structure-activity relationship, has designed and synthesized new platinum complexes to decrease their toxicity. A cisplatin-type complex containing a ferrocenylphosphine moiety was linked with a nucleoside to give the new derivative $\mathbf{1 3}$. This supermolecule could improve significantly the physicochemical properties of the complex with better water solubility, longer half-life, and ease of binding to DNA.<smiles>CC(NC(=O)CCC(=O)NC#Cc1cn(C2OC(CO)C(O)C2O)c(=O)[nH]c1=O)c1cccc(F)c1P(c1ccccc1)(c1ccccc1)(c1ccccc1)c1ccccc1</smiles>

A unique class of estradiol-Pt(II) hybrid complex 14, which binds DNA indirectly through hydrogen bonds, showed good potential in vitro and in vivo for the treatment of hormone-dependent cancers, in particular for breast cancer, without any apparent side effects. When $n$ was 4 , complex 14 was more effective against several types of cancers than cisplatin.

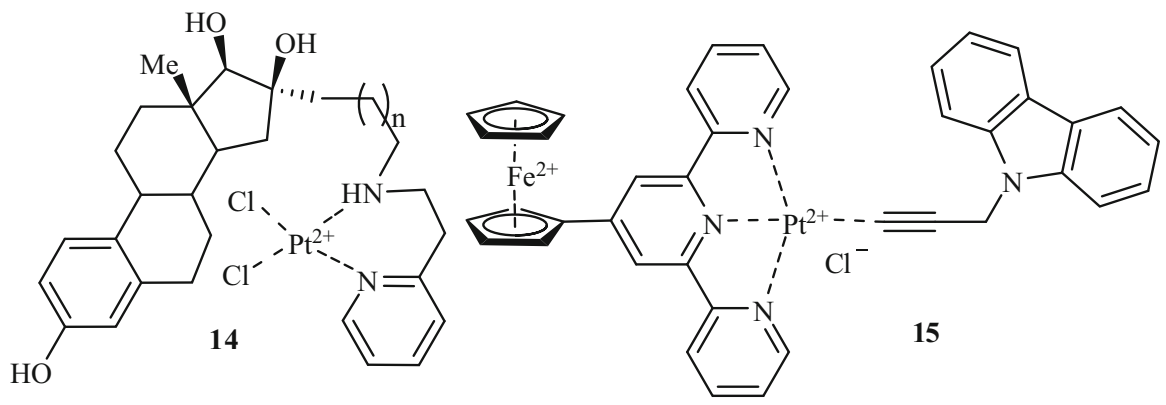


In addition to DNA binding, azole-based platinum supermolecules can also kill cancer cells by photodynamic therapy. The platinum (II) supermolecule $\mathbf{1 5}$ was obtained by ferrocene-modified terpyridine and carbazole derivatives, which could kill human skin keratinocytes under light (400-700 nm). The mechanism of action showed that ferrocene acted as a photoinitiator in the molecule, and after illumination, ferrocene ions were formed. This ion eventually reacted with molecular oxygen to form hydroxyl radicals, oxidizing the surrounding active molecules, causing irreversible damage and thereby killing cells [24].

The synthesis of a unique platinum (II) tethered to a cholesterol backbone was carried out via a unique monocarboxylate and $\mathrm{O} \rightarrow \mathrm{Pt}$ coordination environment that facilitates nanoparticle assembly with a fixed ratio of phosphatidylcholine and 1,2distearoyl-sn-glycero-3-phosphoethanolamine- $N$-[amino (polyethylene glycol)2000]. The formed nanoparticles of $\mathbf{1 6}$ exhibited lower $\mathrm{IC}_{50}$ values in comparison with carboplatin or cisplatin in vitro and were active in cisplatin-resistant conditions. Additionally, the nanoparticles exhibited significantly enhanced in vivo antitumor efficacy in murine $4 \mathrm{~T} 1$ breast cancer and in K-RasLSL/+/Ptenfl/fl ovarian cancer models with decreased systemic and nephrotoxicity. Furthermore, given that platinum-based chemotherapeutics form the frontline therapy for a broad range of cancers, the increased efficacy and toxicity profile indicated that the constructed nanostructure could translate into a next-generation platinum-based clinical agent [25].

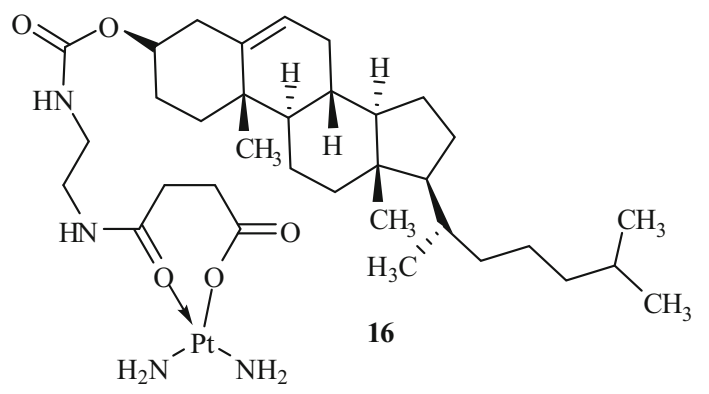

Platinum(IV) complexes possess octahedral geometry. The introduction of two extra ligands, compared to Pt(II) complexes, enhanced their lipophilicity, and offered the opportunity to overcome some problems of platinum(II) drugs. A four-armed amphiphilic copolymer with a metallocycle was established in which the tetraphenylethene derivative acted as an aggregation-induced emissive fluorescent probe for live cell imaging and the 3,6-bis[trans-Pt(PEt3)2]phenanthrene (PhenPt) was an anticancer drug. This copolymer was further self-assembled into nanoparticles of different sizes and vesicles depending upon the experimental conditions, and the self-assemblies were further employed to encapsulate doxorubicin (DOX) to achieve a synergistic anticancer effect. The controlled drug release was also realized via amphiphilicity changes and was driven by a glutathione-induced cascade 
elimination reaction. The DOX-loaded nanoparticles of about $50 \mathrm{~nm}$ in size exhibited excellent antitumor performance as well as low systemic toxicity by the enhanced permeability and retention effect [26].

Multifunctional supramolecular self-assembled nanoparticles were successfully constructed by host-guest interactions. The platinum(IV) prodrug 17 and the porphyrin photosensitizer 18 served not only as the building blocks but also the cargoes of the delivery system. The cellular platinum uptake derived from complex 17-compound $\mathbf{1 8}$ assemblies was much higher than that derived from cisplatin, and visible light irradiation induced the rise of cellular ROS. Therefore, a synergistic enhancement of anticancer efficacy has been achieved. The combination of chemophotodynamic dual therapy was proved to have great potential in overcoming cisplatin resistance [27].
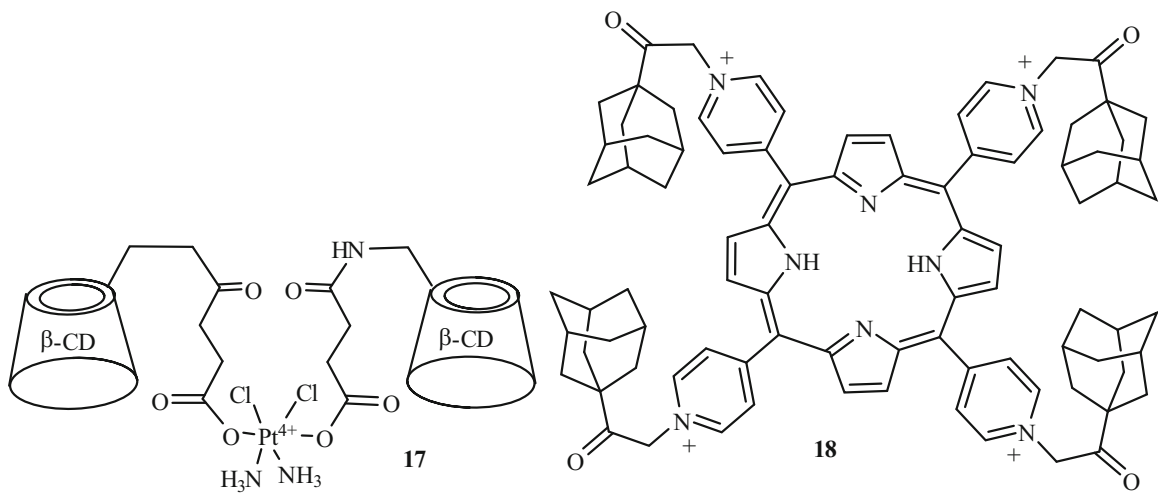

The successful exploitation and wide use of platinum supermolecules as anticancer drugs attracted great interest to investigate other transition metals instead of platinum. Ruthenium complexes have become one of the promising anticancer drugs because of their hypotoxicity and easier absorption by tumor tissue. Currently, most synthesized complexes were monocaryon, including ammonia (imine), multipyridine, ethylenediaminetetraacetic acid, and dimethyl sulfoxide complexes. Generally, the cytotoxicity of ruthenium complexes is related to DNA binding. The anticancer mechanism is that the complexes bind with DNA (covalent bond of guanine residue N7) by cross-linking adjacent Gua once entering into the caryon and then inhibiting the replication of DNA.

Since the initial discovery that $\left[\mathrm{Ru}\left(\eta^{6}-\mathrm{C}_{6} \mathrm{H}_{6}\right)(\mathrm{DMSO}) \mathrm{Cl}_{2}\right]$ could inhibit topoisomerase II, three types of derivatives have been prepared by replacing the DMSO ligand with 3-aminopyridine, $p$-aminobenzoic acid, or aminoguanidine. These analogues enhanced the efficacy of topoisomerase II inhibition and showed higher cytotoxicity against breast and colon carcinoma cells. The aromatic $\mathrm{Ru}(\mathrm{II})$ complex 19 also gave good activity against human ovarian cancer cells and showed similar activity to that of carboplatin with no cross-resistance to cisplatin. 

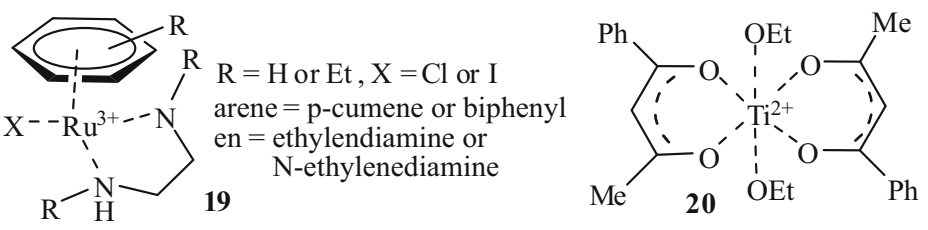

Furthermore, titanium and gallium complex supermolecules have also received much attention and some have been entered into clinical trials. For instance, budotitane 20, first discovered by Keppler in 1982, showed good activity against ascites cancer and solid tumor and better activity against colon cancer than 5-fluorouracil.

Most gallium anticancer compounds in clinical phase I and II studies are inorganic salts of gallium such as gallium nitrate or gallium chloridate. These compounds have better anticancer activity accompanied by stronger toxic side effects. To diminish their toxicity, many organic gallium complex supermolecules were prepared. Complex 21 is now being tested in clinical phases, and the results have shown that the supermolecule $\mathbf{2 1}$ could inhibit prostate cancer and multiple myeloma.

The activity of nitrogen heterocyclic carbene supermolecule $\mathbf{2 2}$ on ovarian cancer TOV21G is comparable to that of the reference drug cisplatin, a promising antiovarian cancer drug. Further studies revealed that when there is no substituent on the phenyl ring or an electron-withdrawing group instead of the methoxyl group, the supramolecular anticancer activity is significantly reduced.

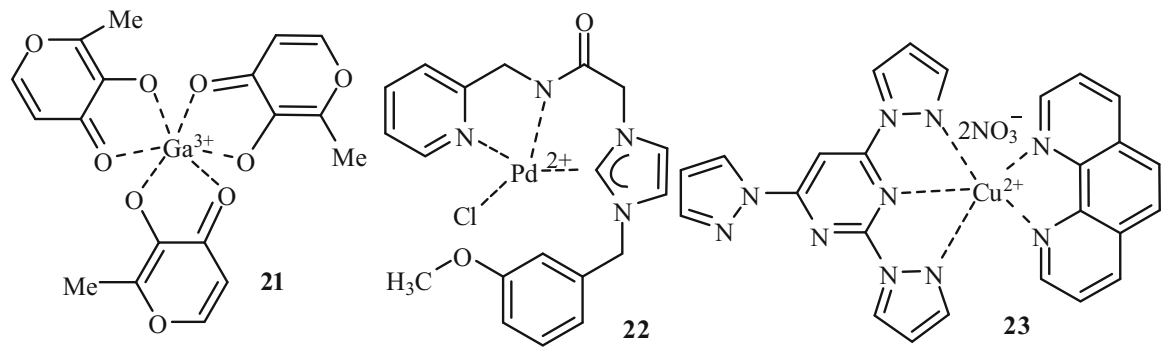

Pyrazole derivative $\mathbf{2 3}$ exhibits broad-spectrum anticancer activity and is effective in inhibiting the proliferation of glioma U373-MG cells, ovarian cancer A2780 cells, leukemia K562 cells, rectal cancer HCT15 cells, breast cancer MCF-7 cells, prostate cancer PC-3 cells, and lung cancer Hop62 cells with a $\mathrm{GI}_{50}$ value of less than $10 \mathrm{~mol} / \mathrm{l}$. The supramolecular molecule exhibits anticancer activity by inhibiting the activity of topoisomerase I.

\section{Polymer-Based Supermolecules as Antitumor Agents}

The solubility, stability, targeting, or safety of some anticancer drugs seriously influences the therapeutic efficacy. These problems could be solved with the help of new drug delivery systems. The most extensive investigation was to use polymers 
as drug carriers. Drugs were encapsulated into the carrier to form various kinds of supramolecular drugs, such as liposomes and nanoparticles. The delivery systems of liposomes and nanoparticles have the merits of increasing solubility, prolonging retention time in vivo, enhancing drug targeting, decreasing toxicity, and overcoming anticancer multidrug resistance. So far many of these supramolecular preparations such as liposomes or nanoparticles have been used clinically. They effectively diminished the side effects, provided prophylaxis of cancer, relieved pain caused by cancer deterioration and chemotherapy, and made it possible to adopt original and better chemotherapy methods for current drugs.

It has long been an important research area worldwide that antitumor agents could be developed as liposomal drugs. Many antitumor liposomes have been developed, such as platinum liposomes, paclitaxel magnetism liposomes, cisplatin invisible liposomes SPI-077, oxaliplatin liposomes (lipoxal), doxorubicin temperature-sensitive liposomes, and doxorubicin long-circulation liposomes (DOXILR). Research showed that encapsulation of doxorubicin in polyethylene glycol-coated liposomes could enhance the safety and efficacy of conventional doxorubicin. In preclinical models, liposomal doxorubicin could produce remission and cure against many cancers including tumors of the breast, lung, ovaries, prostate, colon, bladder, and pancreas, as well as lymphoma, sarcoma, and myeloma. It was also effective as adjuvant therapy. In addition, it was found to penetrate into the blood-brain barrier and inhibit the growth of tumors in the central nervous system. The combination of liposomes with vincristine or trastuzumab resulted in synergistic effects and better efficacy. Liposomes appeared to overcome multidrug resistance, possibly as the result of increased intracellular concentrations and an interaction between the liposome and P-glycoprotein, and showed favorable applications for treating a variety of cancers. Therefore, it is an important trend to improve anticancer drugs by developing liposomes as long-lasting circulation preparations, exploiting a variety of liposomes that are new and aggregate in high concentration in a local tumor.

Nanoparticles are submicron-sized polymeric colloidal particles. In recent years, the clinical values of nanomaterials have been becoming more and more important, and nanoparticles received more attention to act as anticancer drug carriers. Nanotherapy enhanced the drug accumulation in tumor tissue and slowed tumor growth. Some anticancer nanoparticles have been approved by the US FDA for clinical use. Currently, much work focused on nanoparticles of paclitaxel, mitomycin, 5-fluorouracil, doxorubicin, and platinum drugs. Some nano-techniques were also employed to improve PDT therapy. Research revealed that paclitaxel nanoparticles prepared by the nano-precipitation method have activity comparable to traditional formulations, such as the introduction of a solubilizing agent or preparation of cyclodextrins inclusions, with much faster drug-release rate and prolonged action time. Cellular studies showed as much as a 70\% loss of viability in NCI-H69 human small cell lung cancer cells at levels of $0.025 \mu \mathrm{g} \cdot \mathrm{ml}^{-1}$.

An innovative drug delivery system based on a self-assembling amphiphilic dendrimer was developed that can generate supramolecular nanomicelles with a 
large void space in their core to encapsulate anticancer drugs with high loading capacity. The resulting drug-encapsulated nanomicelles can effectively enhance drug potency and combat drug resistance by promoting cellular uptake and decreasing the efflux of the anticancer drug. Moreover, this drug delivery system can significantly reduce the systemic toxicity of the free drug [28].

\section{Supermolecules as Antiinflammatory and Analgesic Agents}

Inflammation is now recognized as a type of nonspecific immune response to a destructive stimulus, and is a basic way to protect the body from infection, irritation, or other injuries. Its clinical appearance includes redness, warmth, swelling, and pain as well as functional disturbance. Antiinflammatory and analgesic drugs are a class of drugs acting against fever and pain, inflammation, and rheumatism. Because of their exceptional antiinflammatory activity, this class of drugs was named nonsteroidal antiinflammatory drugs (NSAIDs) in the 1974 international conference at Milan in Italy. Aspirin is the representative of this type of drug.

Aspirin, the first NSAID used clinically, was a milestone for the use of synthetic drugs to treat inflammation. Subsequently, the NSAIDs expanded to more than 100 varieties and became the first choice to treat osteoarthritis and arthritis pauperum. However, the high gastrointestinal side effects restricted their application. The complexation of NSAIDs with metal ions could significantly reduce gastric toxicity, and some even enhance analgesia and antiinflammatory activities.

Copper-NSAIDs complexes were extensively investigated beginning in 1976. It was found that the antiinflammatory activities of $\mathrm{Cu}$-NSAIDs complexes in animal models were better than the parent NSAIDs. For example, the antiinflammatory activity of the $\mathrm{Cu}(\mathrm{II})$ complex of aspirin was shown to be 30 times higher than the free drug aspirin. Other NSAIDs-metal complexes such as Zn(II), Pd (II), $\mathrm{Sn}(\mathrm{IV})$, and $\mathrm{Ru}(\mathrm{II}, \mathrm{III})$ also decreased toxicity and enhanced the activities of parent compounds.

The zinc complex supermolecule formed with aspirin or niacinamide not only could ameliorate the irritation of aspirin in the gastrointestinal tract but also significantly enhanced antiinflammatory activity. The manganese complex of compound 24 displayed antiinflammatory response as good as that of the parent NSAID sulindac. In addition, the silver (I) complex of compound 25 displayed an antiinflammatory response as good as that of the parent NSAID ibuprofen, respectively [29]. Ruthenium complexes with isonicotinic and nicotinic acids showed antinociceptive and antiinflammatory activity and the mechanism of antinociceptive effect involved in reducing neutrophil migration and inhibiting PKC activation in vivo [30]. Rhodium(III) 26, in the mice model, showed similar antiinflammatory activity to mesalazine [31]. 
<smiles>CC1=C(CC(=O)Nc2cccnc2)c2cc(F)ccc2/C1=C/c1ccc(S(C)=O)cc1</smiles><smiles>CC(C)Cc1ccc(C(C)C(=O)Nc2cccnc2)cc1</smiles>

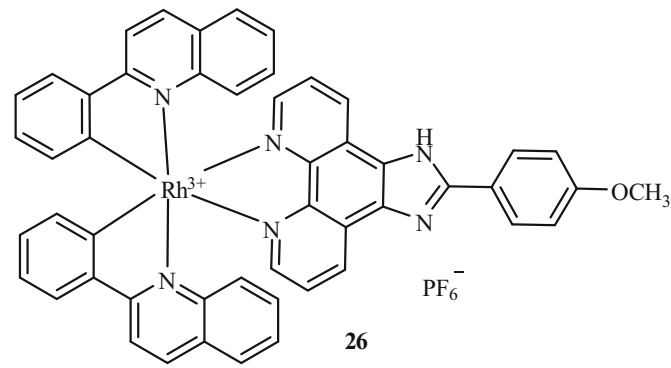

Not only could the NSAIDs metal complexes lower the gastrointestinal damage of NSAIDs, but also the organic complex supermolecules, formed by CDs and their derivatives with NSAIDs, could improve their pharmacodynamics and pharmacokinetics properties. The indomethacin-CD inclusion complex has no anabrosis side effect. Naproxen- $\beta-C D$ significantly increased the water solubility, raised the dissolution rate, facilitated absorption, degraded gastrointestinal damage of naproxen, and also possessed lower photoxicity after complexation with $\beta$-CD. In addition, the ibuprofen- $\beta-C D$ complex also increased the aqueous solubility, absorption rate, and bioavailability of ibuprofen. Coating with $\mathrm{pH}$-sensitive $\mathrm{CD}$ derivatives is a method of drug delivery to the site of action, for example, the antiinflammatory effect of the prednisolone succinate $/ \alpha-\mathrm{CD}(\mathrm{PDsuc} / \alpha-\mathrm{CD})$ inclusion complex, was comparable to those of prednisolone (PD) alone, although its systemic side effect was much lower than that of PD alone when administered orally, which might be related to the specific degradation of the inclusion complex in the large intestine.

Superoxide dismutase (SOD), a new type of antiinflammatory preparation, is an important oxygen free radical scavenger, mainly used for the treatment of patients with inflammation. However, its shortcomings such as high cost, large molecular weight, and low stability prevent its wide use. Many studies have confirmed that nonsteroidal antiinflammatory drugs containing carboxylate ligands and $\mathrm{Cu}^{2+}$ ion could form a metal supermolecule, which displayed SOD activity. The nonsteroidal antiinflammatory drug ibuprofen forms copper (II) complexes 27 and $\mathbf{2 8}$ with imidazole and caffeine, respectively: these can inhibit the conversion of oxygen free radicals with $\mathrm{IC}_{50}$ values of 0.70 and $0.24 \mu \mathrm{g} / \mathrm{ml}$, respectively, which are equivalent or lower than the reference drug ibuprofen calcium salt and natural $\mathrm{SOD}\left(\mathrm{IC}_{50}=0.70 \mu \mathrm{g} / \mathrm{ml}\right)$. 

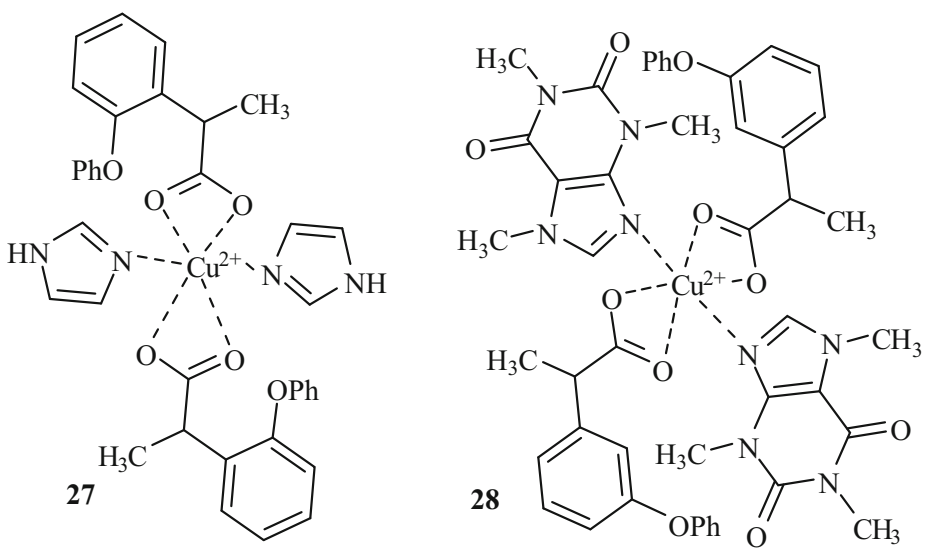

\section{Supermolecules as Antimalarial Agents}

Malaria, one of the most challenging public health problems all over the world, is the most common hazardous parasitic disease worldwide. The rapid expansion of multidrug-resistant parasites has seriously weakened the therapeutic efficacy of antimalarial agents. Thus, it is quite urgent to find new antimalarial agents with different structures and mechanisms for clinical use. Exploring novel antimalarial agents is important for controlling malaria.

Cinchonine 29 is an earlier drug for treating malaria. To improve its water solubility, CDs were employed to form inclusion complexes with cinchonine that might give three types of supermolecules, and these supermolecules improved its solubility significantly. Artemisinin is one of the most widely used antimalarial drugs. However, its low aqueous solubility and shorter half-life resulted in poor and erratic absorption upon oral administration. After encapsulation with CDs, its solubility and oral bioavailability were greatly enhanced.<smiles>C=CC1CN2CCC1CC2[C@H](O)c1cnc2ccccc2c1</smiles>

29<smiles>CN(C)CC1=C(Cc2ccccc2)C2CCCC(C2)C1CNc1ccnc2cc(Cl)ccc12</smiles>

30 Ferroquine(FQ)<smiles>FC(F)(F)c1nc2cc(Cl)c(Cl)cc2[nH]1</smiles>

31

Organic metal complexes as a novel class of antimalarial supermolecules have received close attention. Ferrocene, with its distinct features of sandwich structure and electrochemical behavior, is widely used in biological research and drug design. Ferroquine $\mathbf{3 0}$ is an earlier antimalaria complex containing a ferrocene structure. The survival of mice by treatment with ferroquine was far greater than that of current 
standard drugs, and it also displayed long-term stable antimalarial activity in the biosystem.

Trifluoromethylbenzimidazole $\mathbf{3 1}$ is an anti-protozoal agent that effectively kills protozoa such as Giardia intestinalis, Entamoeba histolytica, Trichomonas vaginalis, and Leishmania mexicana. However, its clinical application has been limited by its low water solubility. An effective way to increase the water solubility, stability, and bioavailability of drugs is to form supermolecules with cyclodextrin. The study showed that complex 31-M $\beta-\mathrm{CD}$ formed by compound 31 and methyl- $\beta$ cyclodextrin $(\mathrm{M} \beta-\mathrm{CD})$ had an $\mathrm{IC}_{50}$ value of $1.9 \mu \mathrm{g} / \mathrm{ml}$ against Leishmania, and its insecticidal effect is far superior to the reference drug amphotericin $\mathrm{B}\left(\mathrm{IC}_{50}=6.5 \mu \mathrm{g} /\right.$ $\mathrm{ml})$ and glucantime $\left(\mathrm{IC}_{50}=18.4 \mu \mathrm{g} / \mathrm{ml}\right)$. At the concentration of $100 \mu \mathrm{g} / \mathrm{ml}, 31-\mathrm{M} \beta$ CD $(82 \%)$ showed much better inhibition than the reference drugs nifurtimox and benznidazole (inhibition rate $<50 \%$ ) against American trypanosomiasis (Chaga disease). In vitro cytotoxicity studies revealed that 31-M $\beta-\mathrm{CD}$ showed a hemolysis reaction greater than $500 \mu \mathrm{g} / \mathrm{ml}$. These studies indicated that 31-M $\beta-\mathrm{CD}$ was expected to be developed as an anti-pathogenic drug.

\section{Supermolecules as Antibacterial Agents}

The frequencies and types of life-threatening infections have been increasing, especially in recent years with the high incidence of multidrug-resistant (MDR), having broken the last line of defense of vancomycin as the antibacterial drug of last report for the treatment of MDR. The synthetic antibacterial agents being used extensively in clinics, such as quinolones and sulfonamides, and antibiotics such as $\beta$-lactam antibiotics and aminoglycoside antibiotics, could not effectively inhibit these bacterial strains; even oxazolidinon, with its new mode of action, cannot meet clinical needs. It is quite urgent to develop novel antibacterial agents with a new mechanism of action and effectively decrease drug-resistant strains.

Numerous investigations have proved that the complexation of antibiotics or potent antibacterial agents to various kinds of metal ions enhances activity and, in some cases, the complexes possessed even more healing properties than the parent drugs. Therefore, to develop and screen new therapeutic antibacterial agents from these active supermolecules is being extensively investigated. According to the structures of the ligands, the supermolecules as antibacterial agents can be divided into the following categories: quinolones, sulfanilamides, Schiff bases, thiosemicarbazides, and macrocycles [32].

\section{Quinolone-Based Supermolecules as Antibacterial Agents}

Quinolones are an important class of synthetic antibacterial agents. Since the introduction of nalidixic acid into clinical practice in 1962, quinolones have been 
developed from the first generation to the fourth generation and are used to treat various kinds of infections. Many researchers have reviewed the mode of action, structure-activity relationship, and activity of these quinolones. It is found that quinolones can bind with DNA mediated by a transition metal. Therefore, it is important to study the coordination chemistry of quinolone antimicrobial agents with metal ions and their antibacterial activities in biology and pharmacy.

Oxolinic acid, OXO, a first-generation quinolone antimicrobial drug, is used for the treatment of urinary tract infections. The complex of oxolinic acid 32a, $\mathrm{Cu}$ $(\mathrm{OXO})_{2}\left(\mathrm{H}_{2} \mathrm{O}\right), \mathrm{MoO}_{2}(\mathrm{OXO})_{2}$, and $\mathrm{UO}_{2}(\mathrm{OXO})_{2}$ showed decreased biological activity in comparison to the free oxolinic acid. Copper(II) complexes of oxolinic acid did not affect the inhibition of the growth of microorganisms significantly when other ligands were introduced, such as 1,10-phenanthroline, 2,2'-bipyridine, and 2,2'dipyridylamine. The complex of cadmium as soft acid and toxic metal ion 32b showed activity against many gram-negative bacteria and Pseudomonas aeruginosa similar to that of cinoxacin.

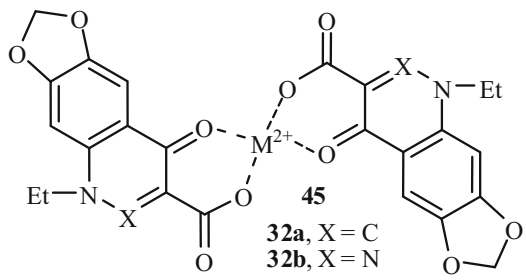<smiles></smiles>

Pipemidic acid is a second-generation quinolone antimicrobial drug that is used to treat gram-negative urinary tract infections and severely damages DNA in the absence of an exogenous metabolizing system. It could form complexes with a series of metal ions such as $\mathrm{Ca}(\mathrm{II}), \mathrm{Sr}(\mathrm{II}), \mathrm{Ba}(\mathrm{II}), \mathrm{Sn}(\mathrm{IV}), \mathrm{La}(\mathrm{III}), \mathrm{Ce}(\mathrm{III}), \mathrm{Pr}(\mathrm{III})$, $\mathrm{Nd}(\mathrm{III}), \mathrm{Sm}(\mathrm{III}), \mathrm{Tb}(\mathrm{III}), \mathrm{Dy}(\mathrm{III}), \mathrm{Y}(\mathrm{III}), \mathrm{Cu}(\mathrm{II})$, and $\mathrm{Mn}(\mathrm{II})$ ions. The reported results suggest that metal ion coordination functions in the antibacterial activity. It was found that among a series of complexes of pipemidic acid with VO(II), Mn(II), $\mathrm{Fe}(\mathrm{III}), \mathrm{Co}(\mathrm{II}), \mathrm{Ni}(\mathrm{II}), \mathrm{Zn}(\mathrm{II}), \mathrm{MoO}_{2}$ (II), $\mathrm{Cd}(\mathrm{II})$, and $\mathrm{UO}_{2}(\mathrm{II})$, the best inhibition is provided by the $\mathrm{UO}_{2}$ (II)complex of supermolecule 33 ( $\mathrm{MIC}=8 \mu \mathrm{g} \mathrm{ml}^{-1}$ ) against Escherichia coli, Pseudomonas aeruginosa, and Staphylococcus aureus.

Norfloxacin is a widely used broad-spectrum antibacterial clinical drug. Many studies have reported the biological activities of the metal complex of norfloxacin, such as silver, tungsten, copper, and auric complexes as well as ternary complexes of copper(II) with norfloxacin. Silver complex 34 of norfloxacin was reported to prevent bacterial infection for humans during burn treatment, and its antibacterial property in topical applications is superior to that of silver and zinc sulfadiazine. In particular, these complexes have better antibacterial activities against $P$. aeruginosa than the free ligand norfloxacin, but lower against Bacillus subtilis. 
<smiles>CCn1cc(C(=O)O)c(=O)c2cc(F)c(N3CCN4CCN(c5cc6c(cc5F)c(=O)c(C(=O)O)cn6CC)CN(C3)O4)cc21</smiles>

\section{Sulfanilamide-Based Supermolecules as Antibacterial Agents}

Sulfonamides are the first synthetic antibacterial agents used in clinics as therapeutic agents against various bacterial infections. In recent years, some metal sulfonamides have attracted much attention because complex supermolecules showed greater activity than both free ligands and the corresponding metallic salts. In particular, Ag-sulfadiazine has been proved to be an effective topical antimicrobial agent, of significance in burn therapy, better than the free ligand or $\mathrm{AgNO}_{3}$. Moreover, some metal complexes of heterocyclic sulfonamides, such as sulfisoxazole, sulfapyridine, sulphadiazine, and sulfathiazole, have been extensively investigated.

The metal sulfisoxazole complex $\mathbf{3 5}$ presented effective antibacterial activity against Staphylococcus aureus, E. coli, and Mycobacterium tuberculosis. Complex 35a presented the same activity against $S$. aureus and $E$. coli as sulfisoxazole, whereas the structurally similar complex $\mathbf{3 5} \mathbf{b}$ was more active against the foregoing bacteria than the free ligand and had no activity against $M$. tuberculosis. Probably the good antimicrobial result occurred because the copper complex 35b can penetrate easily into a less lipophilic cell wall and ionize into the active compounds inside the cell. New gold(I) and silver(I) complexes of sulfamethoxazole $\mathbf{3 6}$ showed better activity against $E$. coli, $P$. aeruginosa, and $S$. aureus than their ligands, which suggested that metal sulfonamide complexes provide possibilities for the development of new antibacterial drugs.<smiles></smiles><smiles>Cc1cc(NS(=O)(=O)c2ccc(N)cc2)no1</smiles>

Sulfadiazine-derived complex $\mathbf{3 7}$ exerted good inhibitory activity against some bacteria; especially, the zinc complex exhibited the best bactericidal potency against Bacillus subtilis and Staphylococcus aureus. These metal complexes performed stronger biological activities than the corresponding ligands and deserved further exploration. 


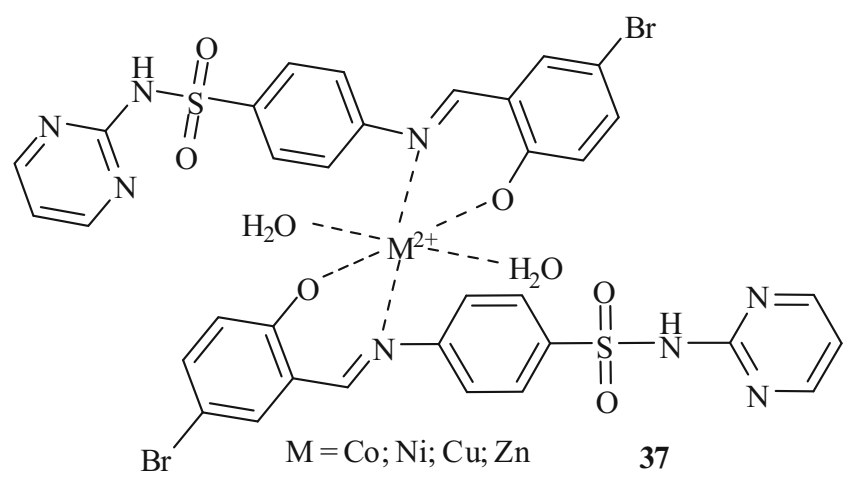

\section{Schiff Base-Based Supermolecules as Antibacterial Agents}

The metal complexes containing oxygen and nitrogen donor Schiff bases possess unusual configuration and structural lability, and they are sensitive to the molecular environment. The environment around the metal center, for example, coordination geometry, the number of coordinated ligands and their donor groups, is the key factor for metalloproteins to carry out specific physiological functions. The Schiff base, containing a phenolic hydroxyl group or aromatic heterocycle with three nitrogen atoms, phosphoric acid, and phosphonate ester as well as their corresponding metal complexes, showed significant antibacterial activities that received considerable attention. Among these complexes, copper complexes were the most important class with good antibacterial activity, and the related work is reviewed here in detail.

The oxygen and nitrogen donor atoms in Schiff bases containing a phenolic hydroxyl group could chelate with many transition metals, showing their biological activity. For example, the Ru(II)-complex of Schiff base derived from vanillin $\mathbf{3 8}$ showed significant activity against Staphylococcus aureus and Escherichia coli, and its antibacterial efficacy was higher than that of corresponding ligands. Structurally similar ligand naphthylideneimine derivatives exhibited little biological activity, but their Ru(II)-complex $\mathbf{3 8}$ showed moderate activity against $S$. aureus and E. coli.
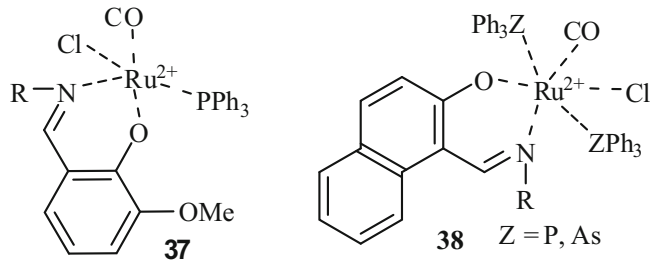

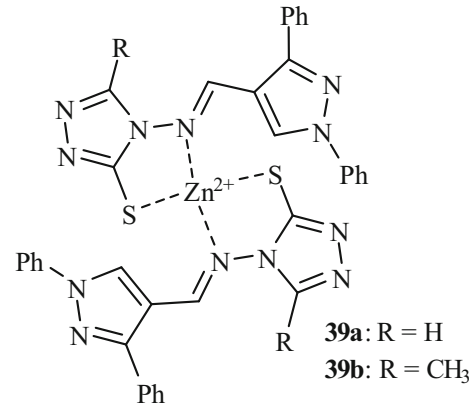


Zinc supramolecular complex 39a showed a better inhibitory ability against Staphylococcus aureus and Bacillus subtilis, with both minimum inhibitory concentration (MIC) values of about $10 \mu \mathrm{g} / \mathrm{ml}$, than the reference drug ciprofloxacin. The inhibitory activity of compound 39a against Escherichia coli and Pseudomonas aeruginosa was not ideal. The structure-activity relationship revealed that the supramolecular complex 39b obtained by introducing a methyl group into the 3position of the pyrazole ring showed equivalent anti-Escherichia coli potency in comparison to ciprofloxacin. The antibacterial activity toward Pseudomonas aeruginosa was also improved. Therefore, complexes 39a and 39b had the potential to become a new type of antibacterial drug after further research.

Moreover, some nonionic Schiff bases showed antibacterial and antifungal potency. The biological activity of their $\mathrm{Cu}(\mathrm{II})$ as well as their Fe(III) complexes being synthesized in ML2 and ML3 stoichiometry have been studied in detail. Comparing with the different Schiff bases, the antimicrobial activity against the fungi Aspergillus niger and A. flavus, and the bacteria Candida albicans, Bacillus subtilis, Staphylococcus aureus, Pseudomonas aeruginosa, and Escherichia coli, was enhanced with increasing length of the alkyl chain. Furthermore, after complexation with $\mathrm{Cu}$ (II) or $\mathrm{Fe}(\mathrm{III})$ ion, the antibacterial and antifungal activities increased as well. In contrast to the other metal complexes, the $\mathrm{Cu}$ (II) complexes showed higher activity against bacteria and fungi. The biological activity of the metal complexes was interestingly decreased when the chain length of the hydrophobic moieties was increased, whereas the contrary trend was observed for the ligands. This difference could be explained by micelle formation occurring more easily for the amphiphilic metal complexes with longer alkyl chains [33].

Complex 40 was found to specifically inhibit the growth of gram-positive bacteria Staphylococcus aureus with $\mathrm{MIC}_{50}$ values of $2-5 \mu \mathrm{g} / \mathrm{ml}$ and completely abolished its growth at $10 \mu \mathrm{g} / \mathrm{ml}\left(\mathrm{MIC}_{100}\right)$. This activity is comparable but slightly lower than the antibacterial activity of a well-known benchmarked antibiotic ciprofloxacin. Insights into the processes controlling intracellular accumulation and mechanism of action were investigated for 40, including the role of ribonucleotide reductase (RNR) inhibition, endoplasmic reticulum stress induction, and regulation of other cancer signaling pathways [34].<smiles></smiles>

\section{Hydrazone-Based Supermolecules as Antibacterial Agents}

The $\beta$-nitrogen atom in carbohydrazones coordinated to the metal atom has an interesting stereochemistry, whereas the $\alpha$-nitrogen remains uncoordinated. 
Complex supermolecules of carbohydrazones showed significant antibacterial, antifungal, and antiproliferative activities, so their research and application suggested enormous potential in the medicinal area.

The complexes of ferrocenyl carbohydrazone or thiocarbohydrazone $\mathbf{4 1}$ displayed moderate antibacterial and antifungal activity, and their activities increased significantly in comparison with their ligands. Ruthenium complexes have been applied in many research areas. The complex $\mathbf{4 2}$ of Schiff base hydrazone containing quinolines showed more effective antibacterial activity. Transition metal complexes of hydrazides and sulfonamides also were found to be used as chemotherapy. The nickel(II) complex of new sulfonyl hydrazone $\mathbf{4 3}$ exhibited moderate activities against gram-positive bacteria including Staphylococcus aureus, Bacillus subtilis, Bacillus megaterium, and the gram-negative bacteria Salmonella enteritidis and E. coli.

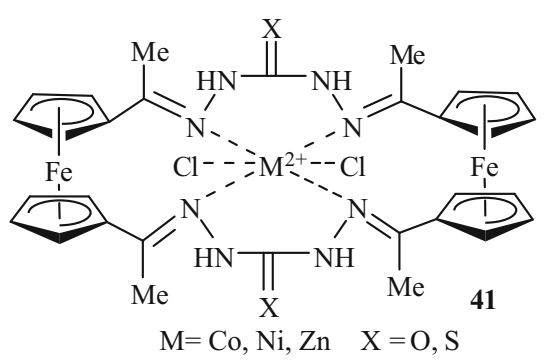

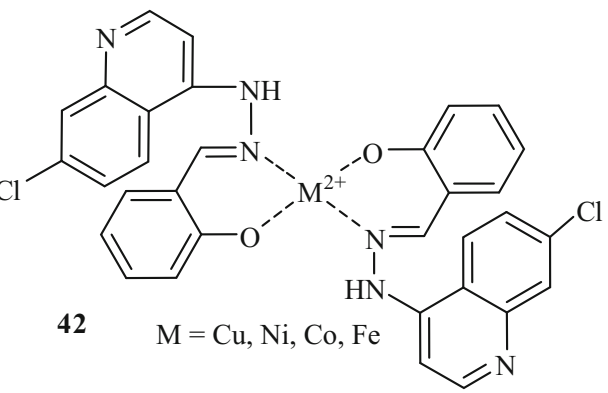

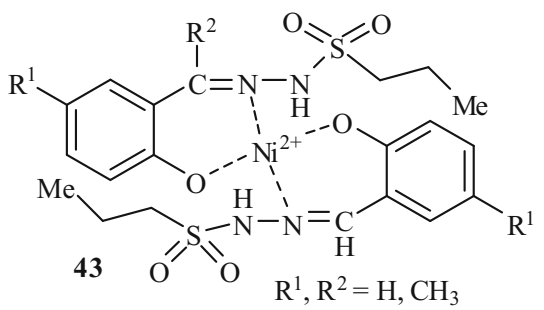<smiles>CN1C(=O)/C(=N\NC(=O)c2cccs2)c2ccccc21</smiles>

The cobalt(II), nickel(II), copper(II), or zinc(II) complex of isatin derivative $\mathbf{4 4}$ exhibited a strong inhibition of the growth of Haemophilus influenzae with MIC values of $0.15-1.50 \mu \mathrm{g} \cdot \mathrm{ml}^{-1}$, and good antibacterial properties toward B. subtilis with MIC values of 3-25 $\mu \mathrm{g} \cdot \mathrm{ml}^{-1}$. These supermolecules also showed good activities against the dermatophyte mold Epidermophyton floccosum.

\section{Thiosemicarbazone-Based Supermolecules as Antibacterial Agents}

Thiosemicarbazones have been considered to be good chelating ligands since the activity of metal complexes of 2-formyl and 2-acetylpyridine thiosemicarbazones was demonstrated in clinically isolated bacteria in the 1990s. Many studies showed 
that thiosemicarbazones had antimicrobial activity, and exhibited significant inhibitory activity to gram-positive bacilli but poor activity to gram-negative bacilli.

Some studies have pointed out that the copper complexes of thiosemicarbazones could be used as novel antimicrobial agents to treat the infectious diseases caused by drug-resistant fungi and bacteria. The copper complexes of pyridine-derived thiosemicarbazones were found to exhibit broad-spectrum antimicrobial activities. The copper complex of compound 45 gave a MIC value of $5 \mu \mathrm{mol} \cdot \mathrm{l}^{-1}$ against the growth of Salmonella typhimurium and $0.5 \mu \mathrm{mol} \cdot 1^{-1}$ against the growth of Candida albicans. The bismuth(III) complexes of morpholine-substituted compound $\mathbf{4 6}$ showed highly selective inhibition toward the growth of gram-positive bacteria Staphylococcus aureus and Bacillus subtilis.<smiles>Cc1cccc(NC(=S)N/N=C(\c2ccccc2)c2ccccn2)c1</smiles><smiles>C/C(=N\NC(=S)N1CCOCC1)c1ccccn1</smiles>

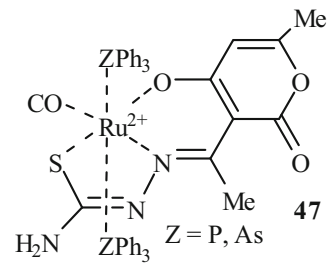

The interaction of small molecules such as $\mathrm{CO}$ and $\mathrm{O}_{2}$ with transition metal complexes, particularly those containing a ruthenium metal center coordinated to nitrogen and oxygen donor ligands, has attracted great interest in recent years. Complex 47 showed good activity against Staphylococcus aureus, Escherichia coli, Candida albicans, and Aspergillus fumigatus. The derivative of 2-hydroxyacetophenone $\mathrm{N}(4)$-substituted thiosemicarbazone 48, and their copper complex showed significant growth inhibitory activity against the bacteria $E$. coli and $S$. aureus and the fungi $C$. albicans and A. flavus. Steroidal thiosemicarbazone palladium complex 49 had the same antibacterial activity as amoxicillin against $E$. coli, Streptococcus pyogenes, and Staphylococcus aureus. The copper complex of pyrrole-2-carbaldehyde thiosemicarbazone $\mathbf{5 0}$ was confirmed to be a broad-spectrum antibacterial agent, with an MIC value of $12 \mu \mathrm{g} \cdot \mathrm{ml}^{-1}$ against Bacillus subtilis and $S$. aureus. Interestingly, it could effectively inhibit the growth of both penicillinsusceptible and -resistant Staphylococcus strains, acted as $25 \mu \mathrm{g} \cdot \mathrm{ml}^{-1}$ toward $S$. cerevisiae, and $50 \mu \mathrm{g} \cdot \mathrm{ml}^{-1}$ toward C. tropicalis and A. fumigatus.<smiles>[R]C(=S)N/N=C(\C)c1ccccc1O</smiles>

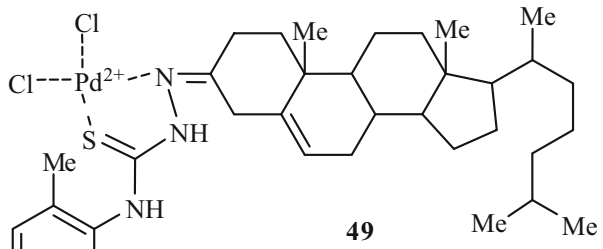<smiles>NC(=S)N/N=C\c1ccc[nH]1</smiles> 


\section{Macrocycle-Based Supermolecules as Antibacterial Agents}

Macrocyclic complexes have attracted great attention because of their pharmacological properties against bacterial and fungal growth. Porphyrins are a class of good photodynamic photosensitizers that can be used for research of the inhibition of bacteria and treatment of various kinds of bacterial infections, and can be also used as a sterilizing agent and antiseptic in hospitals.

The macrocyclic complex $\mathbf{5 1}$ derived from benzil and oxalyldihydrazide was found to exhibit remarkable antibacterial activities against Salmonella typhi, Staphylococcus aureus, and Escherichia coli, and some complexes were equal to standard antibiotic linezolid against the same bacterial strains. Novel macrocyclic Co(II) compounds derived from $o$-phthalaldehyde showed remarkable antibacterial activity; for example, complex $\mathbf{5 2}$ was more active against $S$. aureus, E. coli, and $P$. aeruginosa, compared to streptomycin and ampicillin, and also showed very good efficacy on clinically resistant strains. Nickel(II) complexes of macrocyclic ligand derived from semicarbazide and thiodiglycolic acid $\mathbf{5 3}$ showed that the percentage inhibition of bacterial growth of $S$. aureus was $90 \%$ at the concentration of $0.5 \mathrm{mg} \cdot \mathrm{ml}^{-1}$, and showed good antifungal activity against A. fumigatus.
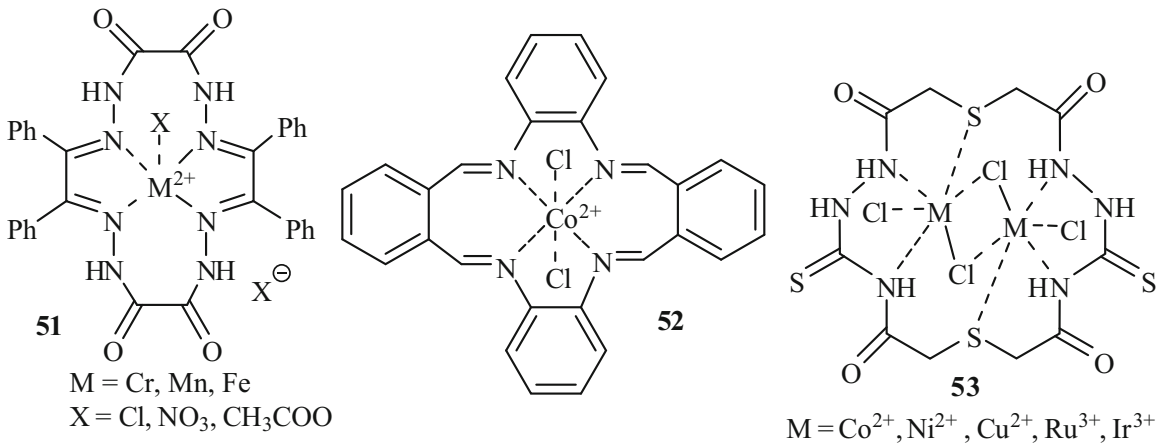

Nickel(II) complexes of polyaza macrocycle 54 were found to decrease in antibacterial activity upon coordination in all cases. However, the macrocyclic dinuclear complex $\mathbf{5 5}$ gave selective antibacterial activity with moderate inhibition toward the growth of $S$. aureus.
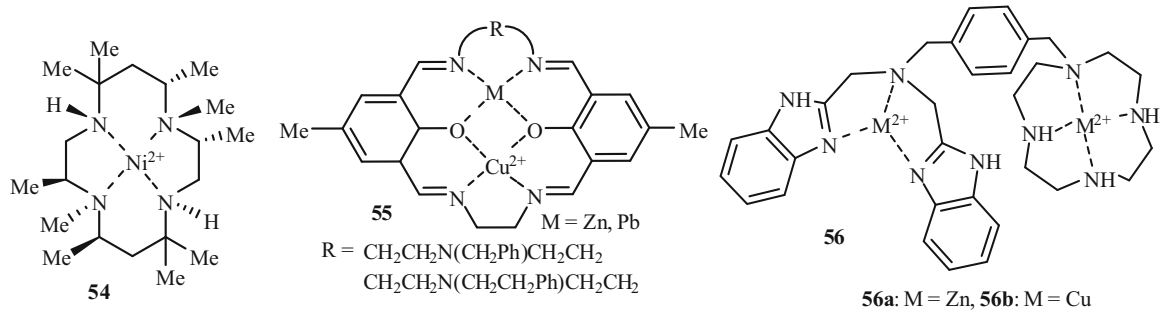

The macrocyclic polyamine 1,4,7,10-tetraazacyclododecane has been extensively studied for its strong ionic coordination ability and important antimicrobial activity. 
Supramolecular molecule 56, a complex formed by macrocyclic polyamine 1,4,7,10tetraazacyclododecane and benzoimidazole derivatives, showed relatively weak inhibitory activity to Escherichia coli and Bacillus subtilis, but had a good growth inhibitory effect on Staphylococcus aureus, Xanthococcus aureus, Pseudomonas aeruginosa, Bacillus proteus, and other strains. The structure-activity analysis found that both metal ion species and bridging benzene linkers had an effect on the antibacterial activity. Complex supermolecule 56a had a very strong inhibitory ability against Pseudomonas aeruginosa and B. proteus, with $\mathrm{MIC}_{50}$ values of 1 and $0.5 \mu \mathrm{g} / \mathrm{ml}$, respectively, being 32 fold and 4 fold better than that of the reference drug chloramphenicol, respectively. However, the antibacterial activity of $\mathbf{5 6} \mathbf{b}$ with a different central ion was significantly reduced, and the $\mathrm{MIC}_{50}$ value of anti-Pseudomonas aeruginosa activity was more than $512 \mu \mathrm{g} / \mathrm{ml}[35]$.

\section{Other Supermolecules as Antibacterial Agents}

Some other metal complexes formed with other structures, including the drug ligands such as tetracycline and vitamins, and others such as chalcone and phenanthroline, also showed antibacterial potential.

Tetracyclines (TC) are broad-spectrum antibacterial agents with effective activity against both gram-positive and gram-negative bacteria, Chlamydia, Mycoplasma, Rickettsia, and protozoan parasites. Other antibiotics of this TC family, doxycycline and chlortetracycline (Chl), showed the same antibacterial activity. Compared to the tetracycline compounds, their corresponding $\mathrm{Pd}(\mathrm{II})$ complex 57 resulted in a significant change of biological activity against $E$. coli. Practically, complex 57a was 16 fold more effective in inhibiting the growth of $E$. coli strains, whereas complex $\mathbf{5 7 b}$ increased its activity in the resistant strain by a factor of 2 fold. Curiously, complex 57c did not improve its activity against the E. coli strain.
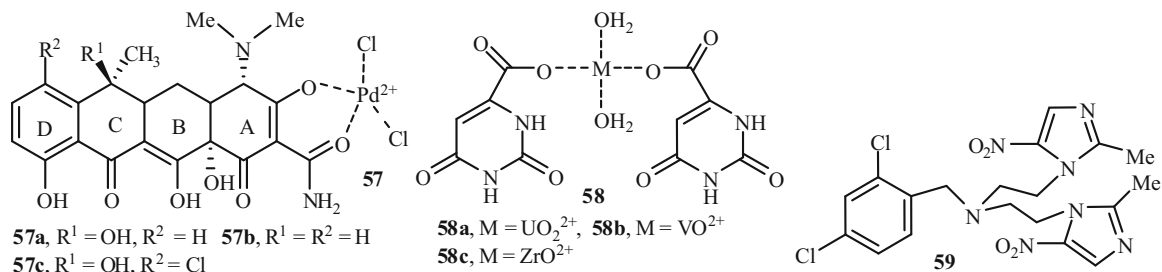

Vitamin $\mathrm{B}_{13}$, belonging to pyrimidine bases in nucleinic acid, is important for cell regeneration in older persons, especially the liver and gastrointestinal tract cells, and is also valuable to be used as an anticancer drug. It is of importance that vitamin $\mathrm{B}_{13}$ and its derivatives could coordinate with many metals to form active biological complexes. The biological assay showed that the synthesized complex $\mathbf{5 8}$ has enhanced activity compared to vitamin $\mathrm{B}_{13}$. The biological activities of metal complexes increase in the order $\mathbf{5 8 a}>\mathbf{5 8 b}>\mathbf{5 8 c}$. Not all the complexes showed better antibacterial activity than their ligands, such as copper and nickel complexes of bis-nitroimidazole $\mathbf{5 9}$ with weaker activity. 
Other complexes of imidazole and picolinamide have also been extensively investigated. Among these studies, many reports concerned copper complexes with stronger biological activity. Most of them showed broad-spectrum antibacterial and antifungal activities and were superior to other metal complexes and their corresponding ligands. The possible reasons are (1) the copper complexes have a proper lipid-water partition coefficient, which enables these compounds to penetrate more easily into the cell and release active matter; and (2) the activated oxygen on the copper surface can inhibit bacterial growth. With the rapid progress of supramolecular chemistry, it would certainly be possible to develop supramolecular antibacterial agents with high efficacy, low toxicity, and a broad spectrum and novel mode of action, to overcome the problem of microbial resistance to current antimicrobial drugs.

The $N$-propenyl-substituted imidazolium nitrogen heterocyclic carbene silver (I) supramolecular complex 60a can inhibit the growth of Staphylococcus aureus and Pseudomonas aeruginosa by destroying the bacterial cell walls, with MIC values for both species about $4 \mu \mathrm{g} / \mathrm{ml}$. The structure-activity relationship showed that the supramolecular complex $60 \mathrm{~b}$ obtained by substituting $\mathrm{Au}^{+}$ions for $\mathrm{Ag}^{+}$ions showed better antibacterial activity than $60 \mathrm{a}$, and the inhibitory potencies against these two bacteria increased by two- and fourfold, respectively. When using the ligand of 60a to form a binuclear macrocyclic supramolecular complex $\mathbf{6 1}$, its antibacterial activity was significantly lower than that of $\mathbf{6 0}$, and the MIC values for both $S$. aureus and $P$. aeruginosa were greater than $100 \mu \mathrm{g} / \mathrm{ml}[36]$.
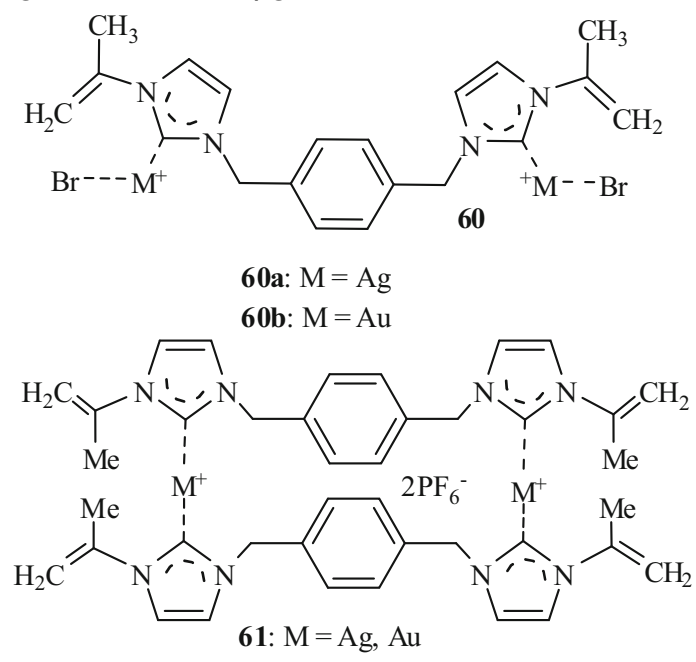

Superamolecule $\mathbf{6 2}$ is formed by a terphenyl-substituted methylene-bridging bipyrazole ligand. Supramolecular complex $62 \mathrm{c}$ had weak inhibitory activity against Bacillus subtilis, but it had a strong inhibitory effect on the growth of Staphylococcus aureus, with an $\mathrm{MIC}_{50}$ of $0.58 \mu \mathrm{g} / \mathrm{ml}$; the inhibitory activity was equivalent to that of chloramphenicol. Compounds 62a and 62c effectively inhibited Pseudomonas putida growth with MIC values of 0.011 and $0.042 \mu \mathrm{g} / \mathrm{ml}$, respectively, and the 
activity was 16 and 4 fold stronger, respectively, than that of the reference drug chloramphenicol. However, the supramolecular complex $\mathbf{6 2} \mathbf{b}$, obtained by replacing chlorine with bromine, showed almost no inhibitory activity on either strains, indicating that the chlorine ligand was of great significance to enhance the antibacterial activity of the supramolecular complex, and that supermolecule 62a had potential to be developed as an antibacterial drug [37].

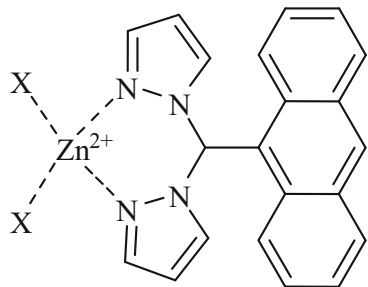

62a: $X=\mathrm{Cl}$
62b: $\mathrm{X}=\mathrm{Br}$
62c: $\mathrm{X}=\mathrm{I}$<smiles></smiles>

63a: $\mathrm{M}=\mathrm{Cu}$

63b: $\mathrm{M}=\mathrm{Zn}$

Phenanthroline is a widely used organic ligand; the $\mathrm{Cu}^{2+}$ ion can cleave DNA by oxidation. The supramolecular complex 63a has a broad antibacterial spectrum and strong antibacterial ability. It exerted comparable inhibitory potency against $\mathrm{Pseu}$ domonas aeruginosa and Escherichia coli to the reference drug tetracycline, and the inhibitory ability against Pantoea dispersa and Bacillus subtilis was twice that of tetracycline. The structure-activity relationship study revealed that the complex $\mathbf{6 3 b}$ formed by replacing the central ion with the $\mathrm{Zn}^{2+}$ ion showed lower inhibitory ability on the foregoing four bacteria than that of 63a, but its activity was still stronger than tetracycline. This finding is important for the further development of triazole antibacterial drugs.

Some chalcone complex supermolecules also showed moderate antibacterial activity against Escherichia coli and Staphylococcus aureus. The octahedral complex proved to inhibit a human rhabdomyosarcoma cell line to nearly the same extent as the cisplatin control, with higher inhibition capacity than the related $\mathrm{Cr}(\mathrm{III}), \mathrm{Fe}$ (III), and Co(II) complexes [38].

\section{Supermolecules as Antifungal Agents}

Fungal infections are one of the leading causes of death of immunocompromised patients. Azole drugs such as ketoconazole and fluconazole are currently prescribed to treat fungal infections caused by the pathogenic yeast Candida albicans. However, many antimicrobial agents are toxic, and their extensive therapeutic use is often accompanied by problems of drug resistance, unwanted side effects, and other difficulties. It is quite urgent to develop new and highly effective antifungal agents.

Mononuclear silver (I) complexes with 1,7-phenanthroline exhibited selectivity toward Candida, effectively inhibiting the growth of Candida albicans, C. parapsilosis, C. glabrata, and C. krusei with MICs ranging from 1.2 to $11.3 \mu \mathrm{M} ; C$. krusei and C. albicans especially were the most sensitive. Complex 64 showed the lowest MIC values and the lowest cytotoxicity against healthy human fibroblasts with SI of more than 30 , and it had the ability to attenuate $C$. albicans virulence and 
reduce epithelial cell damage in a cell infection model. In comparison to silvadene, complex 64 showed a fivefold lower MIC value against $C$. albicans and displayed fourfold lower cytotoxicity. Considering the remarkable activity against all tested Candida species, coupled with the fact that structural differences to other complexes were in the different counterion, complex 64 could be selected for further activity research [39].
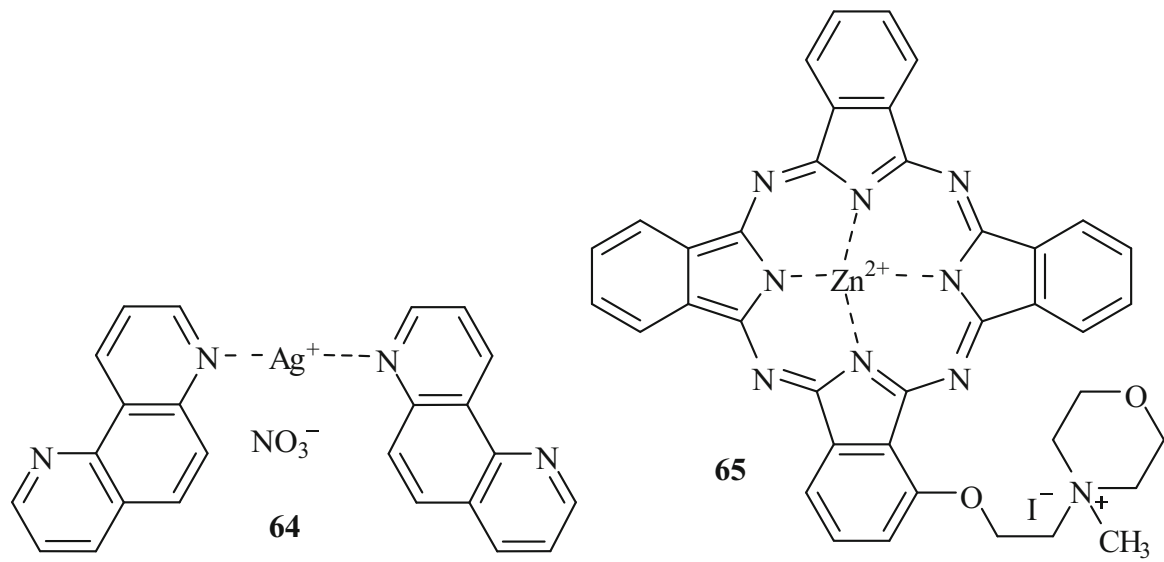

Photodynamic inactivation of pathogenic fungi as a novel antifungal strategy was found to have tempting characteristics such as the avoidance of drug resistance, narrow impairment to the host tissues, and broad-spectrum activity. Furthermore, phthalocyanines have been considered as highly potential second-generation photosensitizers because of their intensive absorption in the red visible light region and high competence in generating ROS. The cationic $\alpha$-mono-substituted $\mathrm{Zn}^{2+}$ phthalocyanine 65 was not only observed with noticeable antifungal photoactivity, with an $\mathrm{IC}_{90}$ value against $C$. albicans as low as $3.3 \mathrm{mM}$, but also presented good photocytotoxicity with high cellular uptake. However, tetra-substitution and $\beta$-substitution with a morpholinyl moiety as well as non-quaternization would cause an adverse effect on its potency attributable to the caused change on hydrophilicity. All these results indicated that complex $\mathbf{6 5}$ holds great potentiality as an intriguing candidate for future studies as an antifungal photosensitizer [40].

The macrocyclic dinuclear $\mathrm{Zn}^{2+}$ complex 56a, produced by combining polyamine with benzoimidazole via a xylyl bridge, possessed low MICs, 0.5 and $8 \mu \mathrm{g} /$ $\mathrm{ml}$, respectively, toward Candida albicans and Aspergillus fumigatus, which was more active than fluconazole. The substitution of the xylyl fragment with the 2,6dimethylpyridyl moiety was not favorable for antifungal efficiency, because the nitrogen in pyridine was likely to decrease the positive charge density and also hindered the approach between molecule and fungus through electrostatic interactions. Also, length was an influencing factor for lipophilicity or hydrophilicity between two metal nuclei, a significant antifungal property. It was also found to be likely to destroy the cell membrane as do quaternary ammonium salt antimicrobial agents. By contrast with the inhibitory action of the mononuclear complex, it was 
shown that dinuclear compounds exhibited more desirable potencies, indicating the importance of the metal ion in antifungal activity [35].

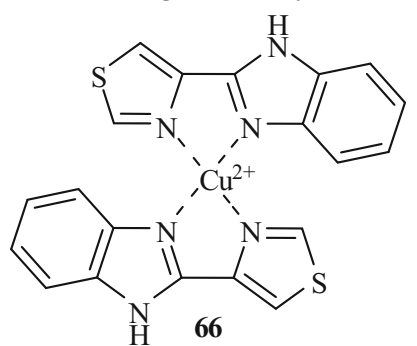

Thiabendazole, with structural similarity to the chelating agents 1,10phenanthroline and 2,2'-bipyridine, is a well-known anthelmintic agent and fungicide in agriculture with poor anti-Candida activity. However, its copper complex 66 was an activity-strong supermolecule with effective inhibition of the growth of $C$. candida strains.

Complexes 67a-c acted as inhibitors against the tested fungal strains with extremely remarkable rates, in the range of $85-99 \%$, in order of Aspergillus sp. $>$ Penicillium sp. $>$ Rhizoctonia sp. The anion participating in chelation also was critical in potency, whereas the acetate was a more beneficial ion for maintaining good activity.

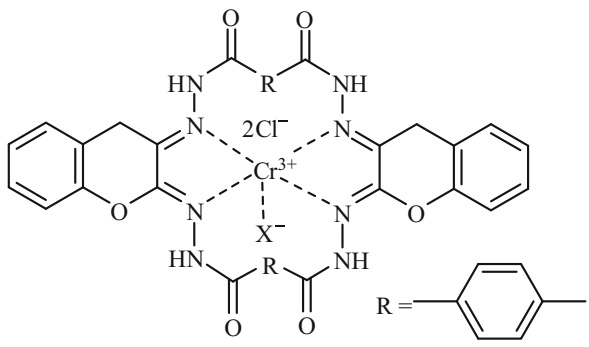

67a: $\mathrm{X}=\mathrm{CH}_{3} \mathrm{COO}$ 67b: $\mathrm{X}=\mathrm{Cl}$ 67c: $\mathrm{X}=\mathrm{NO}_{3}$<smiles></smiles>

Novel organoiridium (III) antimicrobial complex 68, containing a chelated biguanide, including the antidiabetic drug metformin, exhibited high antifungal potent activity against $C$. albicans with MICs in the nanomolar range. The complexes exhibited high selectivity and low cytotoxicity toward mammalian cells. Investigations of reactions with biomolecules suggested that these organometallic complexes delivered active biguanides to the microorganisms, whereas the biguanides themselves were inactive when administered alone. The exchange of monodentate ligands had little effect on the antifungal activity (MICs $=1$ and $0.5 \mu \mathrm{g} / \mathrm{ml}$, respectively). However, the introduction of sulfonyl functional groups could lower the activity slightly [41].

The supramolecular complex $\mathbf{6 9}$, formed by the bipyridine-modified triazole and the $\mathrm{Ni}^{2+}$ ion, has strong inhibition ability against Aspergillus niger, Aspergillus 
flavus, and Candida albicans, and its activity is comparable to that of the reference drug fluconazole. The divalent iron supramolecular complex $\mathbf{7 0}$ obtained by introducing pyridine on its triazole ring is also more active against these three fungi. Further studies have found that the antifungal activity of $\mathbf{6 9}$ is stronger than that of 70, and the activities of the two complexes is significantly higher than that of the corresponding ligands.
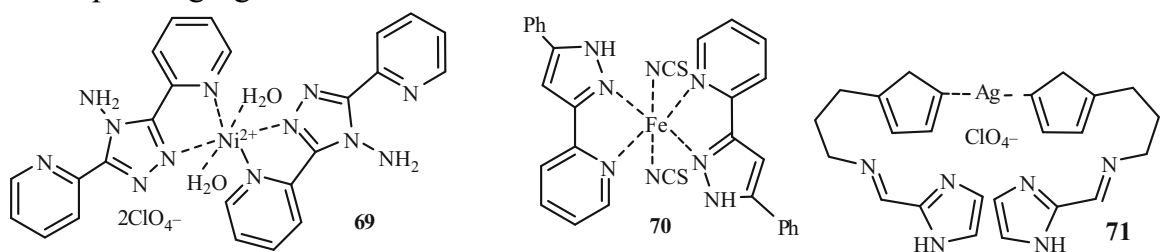

The bis-imidazole silver supramolecular complex $\mathbf{7 1}$ has strong antifungal activity, and its MIC 80 value for Candida albicans is about $7.6 \mathrm{~mol} / \mathrm{l}$. The activity is much better than the reference drug miconazole. The structure-activity relationship showed that when the terminal imidazole ring introduced a methyl group at the N-1 or N-4 position, the anti-Candida albicans activity of the complex supermolecules will be attenuated by sevenfold and onefold, respectively.

The silver supermolecule 72, formed by hydrazine carboxylic acid and two molecules of imidazole derivatives, showed good inhibitory activity against Candida albicans. Further studies indicated that the antifungal activity of this complex is improved significantly when there is no substituent on the imidazole ring. However, the antifungal activity decreased when an electron-withdrawing group was introduced on the imidazole ring, which implied that the substituents affected the antifungal activity of the supermolecules.<smiles></smiles>

\section{Supermolecules as Antituberculosis Agents}

Tuberculosis (TB) is considered to be a highly dangerous infective disease that causes death with a high mortality rate throughout the world. The traditional antiTB drugs, which have been used in clinics for several decades, display multidrug resistance to some extent, which has affected clinical therapeutic efficacy. The long 
treatment cycle of tuberculosis has increased drug resistance and decreased the effectiveness of most available antitubercular agents, resulting in the reemergence of tuberculosis to threaten humans.

Isoniazid (INH) is still one of the important anti-TB clinical drugs because of its distinct antitubercule bacillus activity, and its combination with rifampicin is often used to treat TB in short-course chemotherapy. INH is a good metal ion chelator, and can be coordinated with $\mathrm{Ru}(\mathrm{II}), \mathrm{Mn}(\mathrm{II}), \mathrm{Co}(\mathrm{II}), \mathrm{Ni}(\mathrm{II}), \mathrm{Cu}(\mathrm{II}), \mathrm{Zn}$ (II), $\mathrm{Cd}(\mathrm{II}), \mathrm{Pb}$ (II), and rare earth metal ions to form stable complexes and thus ameliorate their liposolubility. The complex $\mathbf{7 3}$ of INH with $\mathrm{Cu}$ (II), Ni(II), and $\mathrm{Co}$ (II) ions exhibited higher growth inhibition against Mycobacterium tuberculosis $\mathrm{H}_{37} \mathrm{Rv}$ than the parent drug.

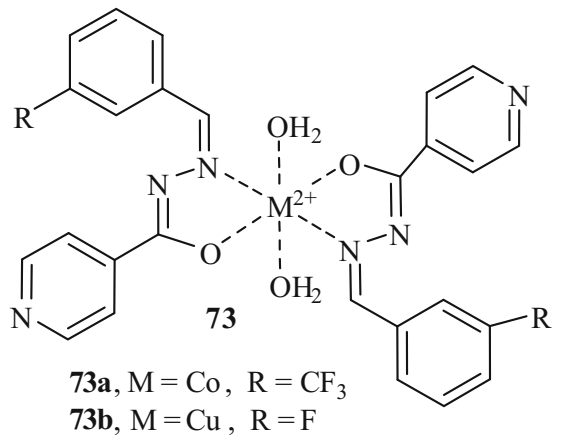

Ciprofloxacin (cf) is often used as an anti-TB drug in clinics. Its application is limited to some extent because of the rapid emergence of drug-resistant strains. Lately, its metal complexes have been found to enhance remarkably the anti-TB activities, such as copper(II) complex $\mathbf{7 4}$ of ciprofloxacin. The formation of organometal complexes possibly increased its liposolubility, making it easier to penetrate into the bacterial cell, and at the same time, $\mathrm{Cu}$ (II) ion was reduced to give copper(I) species intracellularly, resulting ultimately in oxygen activation that is detrimental to the Mycobacteria. This result revealed that metal complexes with reducibility should be valuable for the design of highly active antitubercular drugs. On the basis of this, a mixed-ligand $\mathrm{Cu}$ (II) complex 75 containing ciprofloxacin and phenanthroline was prepared, but this mixed-ligand $\mathrm{Cu}$ (II) complex did not enhance the antitubercular activity, which might be related to phenanthridine to stabilize the cupric species and degrade the reduction activity of cupric species.

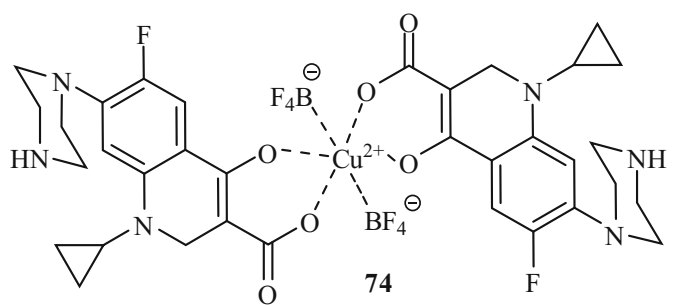

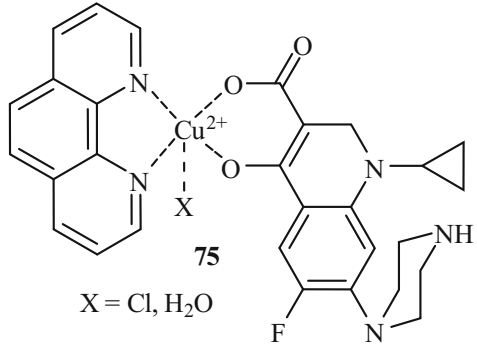




\section{Supermolecules as Antiviral Agents}

Viral infections often result in serious diseases such as hepatitis, acquired immune deficiency syndrome (AIDS), and severe acute respiratory syndrome (SARS) that threaten human health and life. In spite of this, the enormous viral harm to humans did not result in rapid development of antiviral drugs, because virus replication has a close relationship to normal human cells and would damage normal cells when inhibiting the viruses. Similar to other anti-infection drugs, in long-term use antiviral drugs easily lead to drug resistance, decrease the curative effect, and result in relapse. These effects have become quite urgent problems for clinical therapy and drug development to resolve.

Disoxaril is an anti-rhinovirus agent with good activity that was withdrawn from clinical studies by the appearance of asymptomatic crystalluria with large dosages, and the concentration of the drug acting on nasal mucosa was very low. To improve the water solubility of disoxaril, 2,6-di- $O$-methyl- $\beta$-cyclodextrin (DM- $\beta$-CD) was employed to encapsulate the anti-rhinovirus drug disoxaril, forming a 1:1 inclusion complex. It was found that DM- $\beta-C D$ was able to increase significantly the water solubility of disoxaril from $123 \mu \mathrm{g} \cdot \mathrm{ml}^{-1}$ to $471.42 \mu \mathrm{g} \cdot \mathrm{ml}^{-1}$ and efficiently improve the stability of the drugs. A bovine nasal mucosa trial revealed that the formation of inclusion complexes could control efficiently the disoxaril release rate, resulted in a lag time of $2 \mathrm{~h}$, and enhanced the bioavailability of the drugs.

The CD4 cell-surface molecules were the first target of HIV infection; thus, inhibiting the entry of HIV into the cells through receptor CD4 antagonism became a dramatic method to prevent human immunodeficiency virus (HIV) infection. The entry of HIV into cells requires the sequential interaction of the virus with a coreceptor CXCR4; therefore, CXCR4 can serve as a target for the research of new drugs, and this is a new breakthrough for anti-HIV therapy. Bicyclams AMD3100 is a favorable CXCR4 antagonist that can inhibit replication of both $\mathrm{X}_{4}$ and $\mathrm{X}_{4} / \mathrm{R}_{5}$ types of HIV. Compound AMD3100 displayed significant activity against the HIV virus; unfortunately, it was found to have significant heart side effects, leading to its withdrawal from further development as an anti-HIV agent in phase II studies. To improve the anti-HIV activity of AMD3100, the complexation of AMD3100 with metal $\mathrm{Zn}(\mathrm{II}), \mathrm{Ni}(\mathrm{II}), \mathrm{Cu}(\mathrm{II}), \mathrm{Co}(\mathrm{II})$, or $\mathrm{Pd}(\mathrm{II})$ ion produced the 1:2 complex 76, and it was found that the $\mathrm{Zn}$ (II) complex (AMD3479) and Ni(II) complex (AMD3462) were slightly more active than the parent ligand AMD3100. The $\mathrm{Cu}$ (II) (AMD3469) and $\mathrm{Co}$ (III) (AMD3461) complexes were less active than AMD3100, and Pd(II) complex (AMD3158) was virtually inactive.

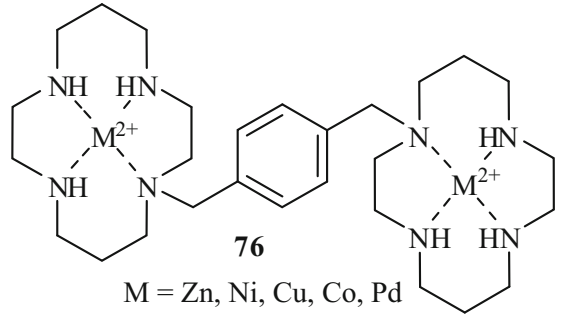


It is has been reported that superoxide dismutase (SOD) can inhibit HIV replication, and an SOD mimic consisting of the manganese SOD complex of a pyridinefused macrocyclic polyamine can inhibit apoptosis in HIV-infected cells by reducing oxidative stress. Novel CXCR4-binding compounds possess anti-HIV activity by evaluating the activities of these macrocyclic polyamines and their complexes with $\mathrm{Mn}^{2+}, \mathrm{Cu}^{2+}, \mathrm{Fe}^{3+}$, and $\mathrm{Zn}^{2+}$ ions. The $\mathrm{Mn}^{2+}$ complex of a new penta-azacyclopentadecane with one fused carbocyclic ring has the greatest potency as an inhibitor of the chemokine receptor CXCR4. The $\mathrm{Zn}^{2+}$ complex 77 was the most potent, and showed that redox activity of the metal center was not associated with CXCR4 inhibitory activity [42].

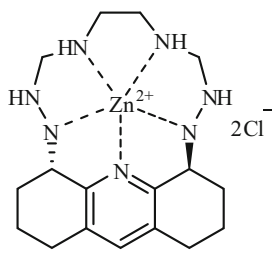

77<smiles>Nc1nc2c(ncn2COCCO)c(=O)[nH]1</smiles>

78

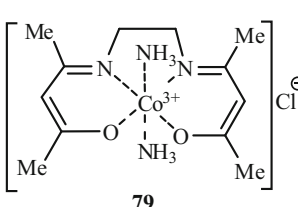

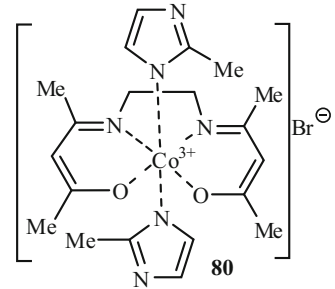

Acyclovir (78) is an efficient nucleobase guanosine antiviral agent that can be transformed into disphosphonate in the body. It could inhibit the replication of herpes simplex virus (HSV) by interfering with DNA synthesis, and has become the first choice against herpesvirus infection. To improve the antiviral activity of acyclovir, many metal complexes of acyclovir with metal $\mathrm{Cd}(\mathrm{II}), \mathrm{Co}(\mathrm{II}), \mathrm{Cu}(\mathrm{II}), \mathrm{Ni}$ (II), $\mathrm{Zn}(\mathrm{II})$, and $\mathrm{Hg}$ (II) ions have been prepared and characterized; however, so far their antiviral properties have not been reported.

Research showed that some Co(III) organic chelates also exhibited favorable antiviral activity. Complex 79 was the first reported Co(III) organic complex with antiviral activity, and it displayed moderate activity against HSV-1. Its analogue CTC-96 (80) exhibited the least toxicity and best activity among this series of complex supermolecules against HSV-1 and HSV-2.

In addition to the foregoing complexes with antiviral activity, the cobalt(III) hexamine complex also exhibited significant antiviral activity. The $\mathrm{IC}_{50}$ values against Sindbis virus-infected cells is $0.13 \mathrm{mmol} \cdot \mathrm{ml}^{-1}$. Ruthenium(II) complex $\left[\mathrm{H}_{4} \mathrm{Ru}_{4}\left(\eta^{6}-p \text {-benzene }\right)_{4}\right]^{2+}$ is active against the polio virus without inhibiting the growth of human cells.

\section{Supermolecules as Antiepileptic Agents}

A large number of experiments revealed that metabolic defects and glutamic acid anomaly may intensify or induce excitotoxicity, and thus result in some neurogenic diseases. Epilepsy is a common neurological disorder, characterized by myoclonus, absence of psychomotor ability, loss of consciousness, paraesthesia, and disorder of 
sensations and movement. Seriously ill patients may suddenly lose consciousness, with tonic-clonic (grand mal) symptom such as screaming, vultus cyanoderma, regurgitating foam, and pupil diffusion; if the seizure lasts for a long time, it may cause a threat to life.

Carbamazepine, a widely used anticonvulsant drug, was absorbed slowly and gave low bioavailability in vivo by its poor water solubility and unstable metabolism. The 1:1 inclusion complex of carbamazepine, formed with $\beta$-cyclodextrin, increased its aqueous solubility, and could reach a sufficient concentration in a minidose through controlling the release rate. Aryl semicarbazones encapsulated with cyclodextrin or its derivatives also can improve the aqueous solubility and bioavailability. For example, the inclusion complex of benzaldehyde semicarbazone 81 with HP- $\beta-C D$, whose minimum dose necessary to produce activity decreased from $100 \mathrm{mg} \cdot \mathrm{kg}^{-1}$ for the free semicarbazone to $35 \mathrm{mg} \cdot \mathrm{kg}^{-1}$, indicating that this inclusion complex significantly increased water solubility, decreased the release rate, and then improved its bioavailability.<smiles>NC(=O)N/N=C/c1ccccc1</smiles>

Some metal-NSAIDs complexes possessed not only antiinflammatory and analgesic activity but also anticonvulsant potential. Many studies of anticonvulsant agents have focused on the copper and zinc supramolecular complexes of NSAIDs, especially the $\mathrm{Cu}_{2}$ (aspirinate $)_{4}$ complexes. The $\left.\left[\mathrm{Cu}_{2} \text { (aspirinate }\right)_{4}(\mathrm{DMF})_{2}\right]$ complex was more effective in inhibiting maximal electroshock seizure (MES)-induced seizures than other binuclear or mononuclear copper chelates of aspirin, but had no activity in the scMET model of seizure. $\left.\left[\mathrm{Cu}_{2} \text { (niflumate }\right)_{4}\right]$ complexes, formed by cupric salt and niflumic acid, showed some activity in inhibiting grand mal and psychomotor-type seizures, and this was consistent with inhibition of electroshockmediated brain inflammation. However, no activity was found for the prevention of petit mal type seizures. Some $\mathrm{Zn}$-NSAIDs complexes have also been proved to possess anticonvulsant activities. Complexes $\left[\mathrm{Zn}(\text { aspirinate })_{2}\left(\mathrm{H}_{2} \mathrm{O}\right)_{2}\right]$ and $[\mathrm{Zn}$ (salicylate $)_{2}($ phen)] were found to have excellent rivalry activity without rotorod toxicity against psychomotor seizures, and complexes [Zn(3,5-DIPS $\left.)_{2}(\mathrm{DMSO})_{2}\right]$, [Zn(aspirinate $\left.)_{2}\left(\mathrm{H}_{2} \mathrm{O}\right)_{2}\right]$, and [ $\mathrm{Zn}(\text { salicylate })_{2}($ phen $\left.)\right]$ exhibited particular useful efficacy in protecting against MES and scMET seizures. In view of the good potential of salicylato-metal complexes in antiinflammatory and anticonvulsant activities, a series of metal $\mathrm{Zn}(\mathrm{II}), \mathrm{Co}(\mathrm{II}), \mathrm{Ni}(\mathrm{II})$, and $\mathrm{Mg}$ (II) complexes with 5-nitrosalicylate was prepared. Only complex $\mathbf{8 2} \mathbf{b}$ was found to exhibit activity against MES-induced seizures, but all the complexes had activity in protecting against the less intense minimal clonic seizure. Their activity order was $82 \mathrm{c}>83 \mathrm{~b}, 83 \mathrm{a}>\mathbf{8 2 a}, 82 \mathrm{~b}, 82 \mathrm{~d}$. Complexes 82a and 83 showed moderate activity against MET-induced seizures, with the relative order of effectiveness of 83a $>\mathbf{8 3 b}>\mathbf{8 2 a}$. 

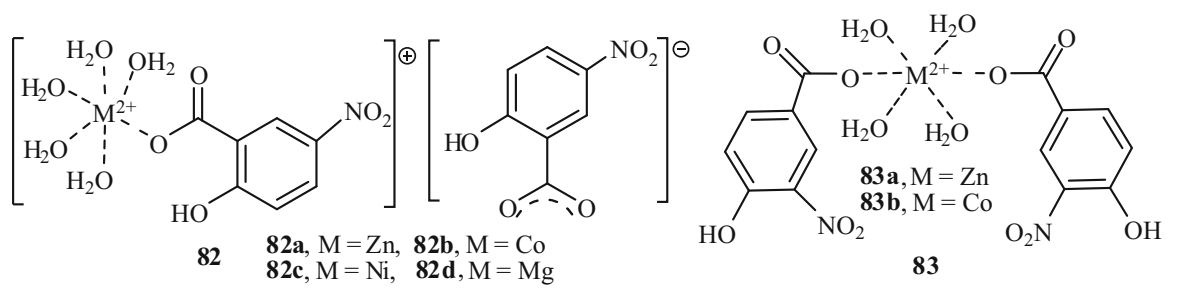

\section{Supermolecules as Cardiovascular Agents}

Cardiovascular disease is one of the major causes of death in developed countries all over the world, and also has gradually become the life-threatening first cause in some developing countries. The cardiovascular drugs have high requirements for drug release; some require quick drug release, whereas others require sustained drug release to decrease the times of administration. The inclusion complexation of cyclodextrin or its derivatives with the available cardiovascular drugs can meet these requirements.

The inclusion complexes of cyclodextrins with the dihydropyridine calcium antagonist could overcome the problems of low solubility and easy oxygenolysis under light. The inclusion complexes of $\beta-\mathrm{CD}$ or HP- $\beta-\mathrm{CD}$ with the drugs nifedipine, nitrendipine, captopril, nicardipine, and nimodipine separately were confirmed to improve effectively the stability, bioavailability, and solubility of these drugs, and the double-layer tablets of nifedipine encapsulated by $2-\mathrm{HP}-\beta-\mathrm{CD}$ and hydroxypropyl cellulose could satisfy the need of differentiated release rate by changing their component ratio. The binary system formed by captopril with HP$\beta-\mathrm{CD}$ or TB- $\beta-\mathrm{CD}$ and the ternary system of captopril/TB- $\beta-\mathrm{CD} / \mathrm{HP}-\beta-\mathrm{CD}$ has been prepared in different molar ratios, and their release behavior was investigated in dogs. It was found that the release rate of captopril from the binary HP- $\beta$-CD system was rather rapid, whereas that from the binary TB- $\beta-C D$ system was comparatively slower, the retarding effect being dependent on the amount of TB- $\beta-\mathrm{CD}$. The release rate from the ternary captopril/TB- $\beta-\mathrm{CD} / \mathrm{HP}-\beta-\mathrm{CD}$ system was slowed by the addition of small amounts of HP- $\beta-C D$, whereas the rate increased as the molar ratio of HP- $\beta$-CD further increased $(>0.25$ molar ratio). The oral administration of the ternary captopril/TB- $\beta-\mathrm{CD} / \mathrm{HP}-\beta-\mathrm{CD}$ system (molar ratio of $1: 0.5: 0.5$ ) in dogs gave a plasma profile comparable to that of a commercially available sustainedrelease preparation. Some studies investigated comparably the solubility-enhancing efficacy of nimodipine by the use of several CDs including HP- $\beta$-CD and their derivatives, finding that HP- $\beta-\mathrm{CD}$ resulted in better solubilizing efficiency than methyl- $\beta-C D$, which may be acceptable for the injectable preparation of parenteral nimodipine solutions. The inclusion complex of triacetyl- $\beta$-cyclodextrin (TA- $\beta-C D)$ with nicardipine hydrochloride (NC) was carried out dissolution investigation in simulated gastric and intestinal fluids in vitro. The results showed that the release 
rate of the inclusion complex was consistent with zero-order kinetics, and it was concluded that TA- $\beta-\mathrm{CD}$ can be used as a sustained-release preparation excipient.

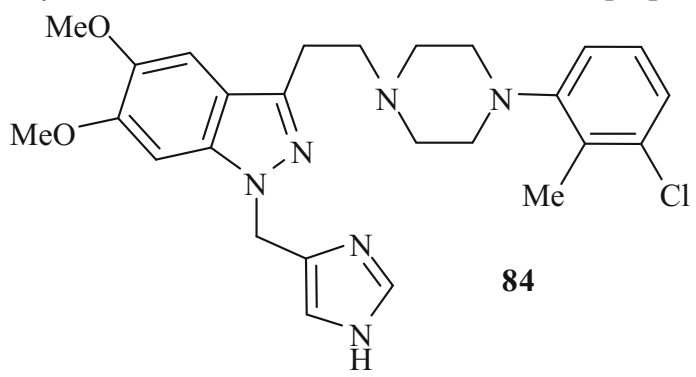

Compound 84 is a novel cytoprotection agent for the treatment of acute ischemic stroke. Compared to neutral HP- $\beta-C D$, the electronegative SBE7- $\beta-C D$ formed a more stable inclusion complex with $\mathbf{8 4}$, resulted in the significant enhancement of water solubility and light stability for drug 84, and also decreased the DY-9760einduced cytotoxicity toward HUVECs and vascular damage in rabbits.

Boronic acid-containing macromolecules have been utilized in a number of biomedical applications, including use in dynamic covalent materials, dual thermoand saccharide-responsive hydrogels, sensors, and nanomaterials, often with the goal of detection and treatment of type 1 diabetes, which requires constant monitoring of blood glucose levels and proactive insulin management. The ability of boronic acids to bind with saccharides and potentially undergo an ionization transition makes the materials ideal for diabetes-related applications. Other biomedical applications of boronic acid containing macromolecules include use as potential HIV barriers, separation and chromatography, cell capture and culture, enzymatic inhibition, and in site-specific radiation therapy [43].

A closed-loop "smart" insulin delivery system with the capability to mimic pancreatic cells will be highly desirable for diabetes treatment. Researchers have reported a multi-stimulation-responsive insulin delivery platform based on a clear supramolecular strategy. Self-assembled from a well-designed amphiphilic host-guest complex formed by pillar arene and a diphenylboronic acid derivative, and loaded with insulin and glucose oxidase, the obtained insulin-GOx-loaded supramolecular vesicles can selectively recognize glucose, accompanied by the structure disruption and efficient release of the entrapped insulin triggered by the high glucose concentration. A hyperglycemic condition, as well as a low local $\mathrm{pH}$ and a high $\mathrm{H}_{2} \mathrm{O}_{2}$ environment generated during the GOx-promoted oxidation of glucose to gluconic acid could facilitate the rapid disassembly of the vesicles and achieve efficient insulin release. More importantly, in vivo studies by using a mouse model of type 1 diabetes further showed that the insulin-GOx-loaded vesicles could regulate the blood glucose levels to a normal range during prolonged periods with fast responsiveness [44].

Advanced therapeutic modalities such as heart transplantation have been developed and considered to be the optimum paradigm for the treatment of a diseased heart. However, such a surgical operation is applicable to only a small subset of 
patients because of donor organ shortages and the incidence of immune rejection. Therefore, the development of effective therapeutic strategies for the prevention and treatment of thrombotic diseases is a demanding priority. Recently, supramolecular hydrogels self-assembled from peptide derivatives have shown great promise in cardiovascular diseases and regenerative medicine. The researchers combined curcumin with NO in a mixed-component hydrogel 139 to treat myocardial infarction (MI) by intramyocardial injection [45].

A supramolecular hydrogel formed by self-assembly of folic acid (FA)-modified peptides by a biocompatible method (glutathione reduction) was reported that is suitable for cell encapsulation and transplantation. iPS cells labeled with CM-Dil were transplanted into MI mice hearts with or without FA hydrogel encapsulation. The results confirmed that FA hydrogel significantly improved the retention and survival of iPS cells in MI hearts after injection, resulting in enhanced therapeutic efficacy of iPS cells, including better cardiac function and less adverse cardiac remodeling, followed by cardiomyocytes [46].

The incidence of diabetes is becoming higher and higher, and the diabetes patients are being diagnosed younger and younger, which has aroused great concern around the world. Some related work has been devoted to the development of hypoglycemic drugs such as tolbutamide, metformin, and rosiglitazone, widely used in clinical practice. Studies have shown that azole heterocyclic complex supermolecules have high bioavailability and weak drug interactions. Azole heterocyclic complexes have an important role in reducing insulin resistance and enhancing insulin secretion, opening up a new orientation for the development of new and highly effective antidiabetic drugs [47].

Angiotensin II (AII) causes vasoconstriction and increases blood pressure, leading to high blood pressure. Currently, the sartan type of drugs can be used orally for the treatment of hypertension, atherosclerotic lesions, and diabetes, when combined with the subtype AT1 receptor of the AII type. The antihypertensive drug telmisartan 85 is potent because of its strong binding to angiotensin II receptors. Studies have shown that after forming a complex with metal ions, the mechanism of action is not changed. When the divalent copper ion forms a complex with the telmisartan 85, its antihypertensive effect is enhanced.<smiles>CCCCc1nc(Cl)c(C(=O)O)n1Cc1ccc(-c2ccccc2-c2nnn[nH]2)cc1</smiles> 
The antihypertensive drug losartan $\mathbf{8 6}$ is a tetrazole derivative that forms a watersoluble inclusion complex with hydroxypropyl- $\beta$-cyclodextrin, where there is a short-range interaction between Los and hydroxypropyl- $\beta$-cyclodextrin. The antihypertensive activity of the formed inclusion complex was evaluated. The results showed that the oral effect was good, the antihypertensive control was effective, the action time was increased from $6 \mathrm{~h}$ to $30 \mathrm{~h}$, and the time and extent of antagonism had been strengthened.

\section{Supermolecules as MRI Agents}

Magnetic resonance imaging (MRI) is a special imaging technique with multiple parameters and polynucleation. Its physical principles are the use of a special frequency of electromagnetic waves to irradiate the human tissues placed in the magnetic field, resulting in the nuclear magnetic resonance of hydrogen atoms in different tissues. The electromagnetic waves are absorbed and then emit the socalled nuclear magnetic resonance (NMR) signal. This NMR signal shows the internal structural information of matter, and the latter is measured and analyzed for the corresponding physical and chemical information. Thus, this technique exhibits important application values in such fields as physics, chemistry, biology, and medicine.

Since Lauterbur first used MRI in 1973, the MRI technique has been widely used in various biomedical domains as clinical diagnosis with no traumatic occlusion and multi-contrast. Whether in clinical diagnosis or fundamental research, MRI has currently become an indispensable tool. Its distinct feature is that the images are very clear for soft tissue. Up to the present, no other diagnostic imaging can be compared with MRI.

Metal ions, such as Gd(III), Dy(III), Fe(III), and Mn(II) with large magnetic moments, could form stable chelates by chelation with appropriate ligands. These complex supermolecules may decrease toxicity and increase molecular volume, and have become the chief objects in the research of MRI contrast agents. Free Gd(III) with hydration water and most of its corresponding complexes were not compatible with venous blood, easily precipitated, and exhibited strong toxicity. Therefore, it was of importance to choose a series of Gd complexes that are stable in blood or humor. The first magnetic resonance contrast medium Gd-DTPA, the Gd(III) complex of diethylene triaminepentaacetic acid (DTPA), was developed by Schering AG, and was used in clinics in 1983. To date, nine Gd(III) complexes have been used as MRI contrast agents: Magnevist (87a), MultiHance (87b), Primovist (87c), Vasovist (87d), Omniscan (87e), OptiMARK (87f), Dotarem (88a), ProHance (88b), and Gadovist (88c). Besides Gd(III) complexes, the Mn-DPDP complex Teslascan (89) has also been entered into clinical practice. 


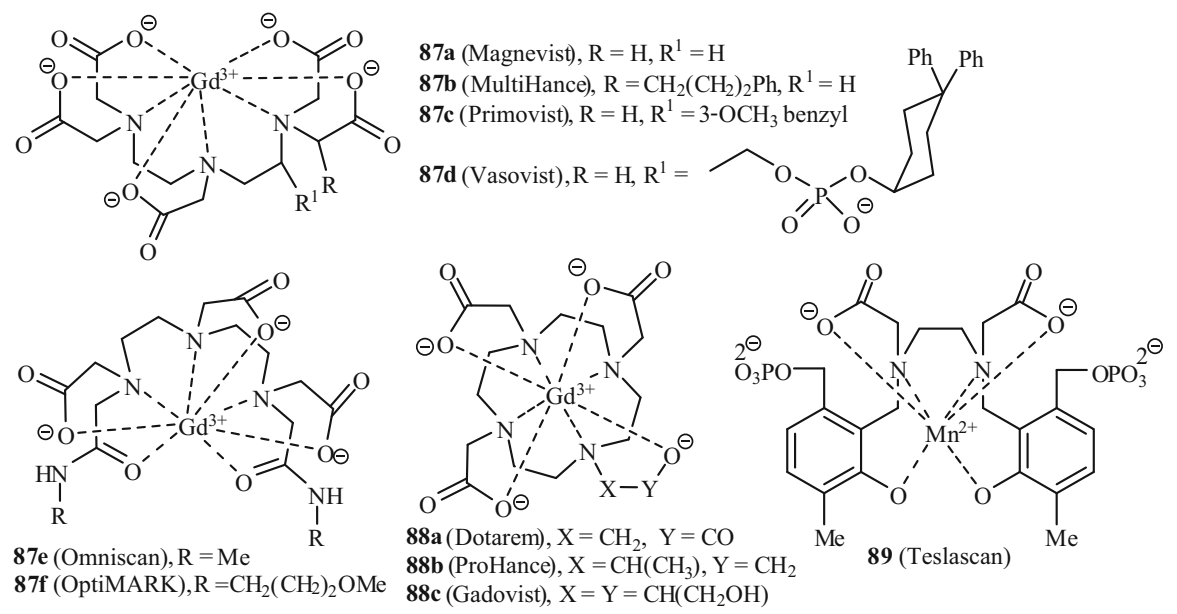

Recently, the development and application research on contrast agents has mostly focused on the improvement of the ligands, and Gd(III) was generally chosen as the metal ion. The ligands included both linear and macrocyclic compounds. The current design has been primarily oriented on modifications of the structural motifs of DOTA and DTPA to improve their selectivity and biocompatibility. Much effort in the development and application of contrast agents has been mainly expended in two following aspects.

The first is to modify the ligands to reduce their toxicities and increase their stability and selectivity. The introduction of some functional groups in the modification of the ligand backbone of the contrast agents could ameliorate their hydrophobicity to obtain tissue- or organ-specific contrast agents. Currently, major research fields are involved in three types of targeting contrast agents including liver-targeting agents, tumor-targeting agents, and blood pool agents. Some hydrophobic groups, such as long-chain bisamide, aliphatic moiety, and phenyl ring, have been incorporated into the backbone of these complexes to increase their hydrophobicity and facilitate their selective absorbance by hepatic cells, therefore possessing great potential as liver imaging contrast agents. The contrast agents $\mathrm{Gd}(\mathrm{BOPTA})$ and Gd(EOB-DTPA) are in the clinic trials stage.

Supramolecular complex Gd-DTPA is a MRI contrast agent being used extensively in clinics. It is an ionic contrast agent with high osmotic pressure and short detention time in vivo, and is easy to eliminate through kidney metabolism, as well as having no tissue or organ specificity. Complex Gd-DTPA was modified to form electroneutral molecules, and thus exhibited much lower osmolality and toxicity in animals. The reaction of Gd-DTPA with bisamides produced bisamido non-ion ligands such as Gd(DTPA-BDMA), Gd(DTPA-BDEA), Gd(DTPA-BIN), and Gd (cyclic-DTPA-1, 2-pn). Animal experiments and MRI evaluation showed that four neutral Gd-DTPA bisamide derivatives gave good relaxation in bovine serum albumin, and possessed features of liver targeting, better water solubility, 
hypotoxicity, and long detention time in vivo. The Gd-DTPA derivative 87d showed favorable binding ability with human serum albumin (HSA) by using a bulky hydrophobic residue consisting of two phenyl rings attached to a cyclohexyl moiety link, and reduced filtration of the glomerulus monomer, which resulted in low renal excretion rate and prolonged half-life time in blood vessels. Complex 87d is also the first Gd(III)-based contrast agent for angiographic applications to proceed to human trials. A series of DOTA derivatives $\mathbf{9 0 - 9 3}$ has been prepared with liver targeting; their supramolecular complexes displayed higher relaxivity than standard $\mathrm{Gd}$ (DTPA) and Gd(DOTA). The Gd(III) complexes of the piperidine-backboned PIPDOTA and PIP-DTPA displayed reduced kidney accumulation, compared with the nonspecific $\operatorname{Gd}(\mathrm{DOTA})$. The strategy to increase lipophilicity and rigidity of the chelate system and thus enhance hepatobiliary clearance and complex stability by incorporating either a piperidine or an azepane ring into the DTPA system appears desirable for the design of liver-specific MRI contrast agents. Gd(III) complexes of compounds 90-93 are promising to act as MRI liver agents or nonspecific agents in the clinic.

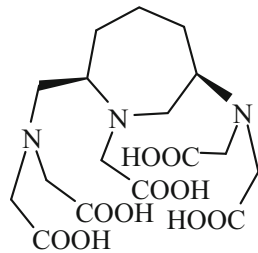

90 AZEP-DTPA

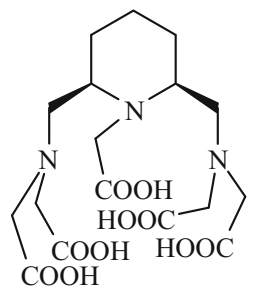

91 PIP-DTPA

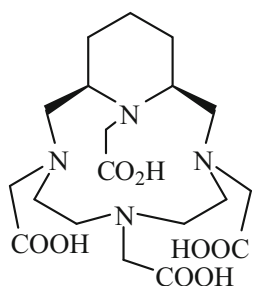

92 PIP-DOTA

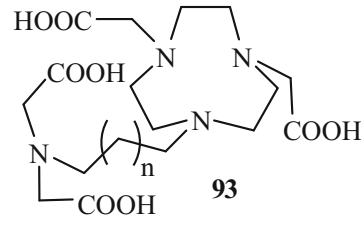

93a, $\mathrm{n}=0 \quad$ NETA 93b, $n=1 \quad$ NPTA

Recently, many studies have focused on Gd-DOTA derivatives. The complex P760 (94), a gadolinium macrocycle based on a DOTA structure that is substituted by hydrophilic bulky groups, had higher relaxivity and good biocompatibility. In rabbits, $5 \mathrm{~min}$ after the injection of 94, the blood concentration of $1036 \pm 105 \mu \mathrm{mol} \cdot \mathrm{kg}^{-1}$ was equivalent to the blood concentration of Gd-DOTA $1 \mathrm{~min}$ after injection. Furthermore, the slow permeability process increased the sensitivity of $\mathbf{9 4}$ for revealing permeability abnormalities, especially for tumor detection, and it displayed potential application.<smiles>[R]CNCC(=O)Nc1c(Br)c(C(=O)OCC(O)CO)c(Br)c(C(=O)OCC(O)CO)c1Br</smiles>

Another aspect in the exploitation and application of contrast agents is to couple with macromolecule covalently, resulting in enhanced relaxation efficiency and targeting property. 
The DTPA and DOTA were introduced by polyester or polyamide into the backbone of a polymer, or coupled covalently with natural or artificial synthetic polymers, to be capable of forming macromolecular MRI contrast agents. They could decrease molecular spin rate, increase relaxivity, maintain stable concentration for prolonged times in blood vessels, and further profit angiography; thus, these compounds were called blood pool contrast agents. In addition, when an organ- or tissue-targeting group was attached to this macromolecular metal complex, it could be endowed with an organ- or tissue-targeting property.

The Gd chelates of DTPA derivatives coupled with the deoxycholic acid moiety had a higher relaxivity and longer half-life in human blood. Preliminary clinical tests showed that $T_{1}$ decurtated to about $100 \mathrm{~ms}$ when injected at $50 \mathrm{mmol} \cdot \mathrm{kg}^{-1}$, and had good visualization effective for arteria coronaria in $30 \mathrm{~min}$.

The Gd-DTPA derivatives in covalent conjugation with the surface of polyamidoamine dendrimer separately form dendritic chelates that exhibited higher relaxivities than Gd-DTPA. The macrocyclic Gd(III) complexes formed by the conjugates of polyamidoamine (PAMAM) backbone with macrocyclic polyamine Gd(III) complexes could decrease the internal mobility of the MRI photographic developer, enhance its relaxivity efficacy, and could be used as a $\mathrm{pH}-$ responsive MRI contrast agent in vivo.

The excellent efficacy of MRI contrast agents enables them to be an important assistant method in daily application. The first liver-targeting contrast agent is on the market, and lymph and blood pool contrast agents will also be marketed soon. In the near future, diseased region- or organ-targeting contrast agents with wide application will become a basic tool in medical diagnosis imaging. With the development of new MRI techniques, such as MR angiography (MRA), perfusion MRI, and diffusionweighted MRI and their extensive use in clinical diagnosis, the research and development of MRI contrast agents will be faced with greater challenges. The major trends in the research and development of MRI contrast agents will focus on tissue- or organ-targeting materials with high relaxivity and specificity, high contrast enhancement with low doses, low toxicity and side effects, and minimal expense. Along with the progress of biocoordination chemistry, NMR spectroscopy, and medicine, there is no doubt that more and more novel, highly effective, and lowtoxicity contrast agents will be used in the clinic and bring more human benefits.

Dinuclear (Ir. $\mathrm{Ln})$ and trinuclear $\left(\operatorname{Ir} \cdot \mathrm{Ln}_{2}\right)$ complexes, in which a phosphorescent Ir (III)-based unit is connected to one or two water-stable lanthanide/aminocarboxylate units via a rigid, conjugated bridging connection, have been prepared. The dinuclear complexes performed better than their trinuclear counterparts for luminescence cell imaging and also in terms of relaxivity (for Gd complexes). Dinuclear (Ir. Ln) complexes performed best in cellular studies, exhibiting good solubility in aqueous solutions, low toxicity after 4 and $18 \mathrm{~h}$, respectively, and punctate lysosomal staining. For dual (luminescence + MRI) imaging applications, the complex $\mathrm{Ir} \cdot \mathrm{Gd}$ is a promising candidate. With excellent luminescence imaging capabilities and low toxicity, it also displays unusually high relaxivity for a small molecule containing just one $\mathrm{Gd}$ (III) center. Variations in luminescence lifetime allow it to be used as a sensor toward molecular oxygen, an important biological analyte, in solution and in vitro [48]. 


\section{Supermolecules as Other Medicinal Agents}

Diabetes mellitus has become one of the most serious diseases threatening human health, and research and development of antidiabetic drugs has become increasingly active [49]. Insulin is the most effective and the first choice in the treatment of advanced-stage diabetes. However, polypeptide drugs such as niditas insulin can aggregate by the interaction of internal hydrophobic residues and are often accompanied by drastic reduction of biological potency. The application of CD complexation represents a unique and effective strategy for improving drug solubility and activity by stabilizing against aggregation. The prepared HP- $\beta-C D-i n s u l i n$ complex, encapsulated mucoadhesive nanoparticles, could protect the insulin from proteolytic degradation, resulting in good oral insulin delivery systems. With polypseudorotaxanes of pegylated insulin with CDs as the supramolecular system, it was found that the release rate of insulin in the $\gamma$-CD polypseudorotaxane was lower than that of insulin alone, and the $\gamma$-CD polypseudorotaxane could prolong the hypoglycemic effect of insulin in rats. The results indicated that the pegylated insulin/CD polypseudorotaxanes could work as a sustained drug-release system. Tolbutamide (TBM) was used clinically in tablet form as an oral hypoglycemic agent, and the inclusion complex of TBM with $\beta-\mathrm{CD}$ or HP- $\beta-\mathrm{CD}$ increased its aqueous solubility, dissolution rate, and oral absorption rate. Metal vanadium, a trace metal ion in higher animals, was well known to be essential to some organisms, and the vanadium complex VO-Hglu of D-gluconic acid as an antihyperglycemic agent showed good efficacy, with the need for further development as a potential drug.

Inclusion research on tacrolimus showed that the complex of $\beta$-CD with tacrolimus gave the highest stability constant among natural $\alpha-, \beta-$, and $\gamma$-CDs, which indicated that the cavity of $\beta-\mathrm{CD}$ matched well with tacrolimus. Rocuronium bromide is frequently used as a neuromuscular blocking agent in surgery. However, a reversal agent, for example, neostigmine as inhibitor of acetylcholinesterase (AChE) with side effects of bradycardia, nausea, and vomiting, was often administered to facilitate rapid neuromuscular recovery after surgery and to prevent residual blockade. However, the reversal agent could cause the side effects of bradycardia, nausea, and vomiting. The prepared $\gamma$-CD-rocuronium bromide inclusion complex as revealed by X-ray crystallography analysis showed that the complex was stable in the cavity of $\gamma$-CDs, which blocked the pharmacoactivity of rocuronium indirectly. The $\gamma$-CD derivative rapidly reversed the neuromuscular blocking effect of rocuronium bromide in vitro (mouse hemi-diaphragm) and in vivo (anaesthetized monkeys), and appeared to be superior to neostigmine without any toxicant side effects; it now has entered into the clinical trial stage.

Alzheimer's disease (AD) is a common neurological disease that is associated with depositional oxidative damage of insoluble $\beta$-amyloid $(\mathrm{A} \beta 40, \mathrm{~A} \beta 42)$ and decrease in acetylcholine. To date, clinical drugs have not been able to cure Alzheimer's disease, but only to maintain the function of acetylcholine and glutamate channels to limit the side effects of the disease. Recent studies have found that the histidine that acted on insoluble $\beta$-amyloid can significantly reduce the neurotoxicity of $\beta$-amyloid. Therefore anti-insoluble $\beta$-amyloid deposition is currently the 
main target for the development of AD drugs. The development of supramolecular drugs has become an active field in the treatment of AD. Although metal chelators are rarely explored as $\mathrm{AD}$ therapies, copper complexes could feasibly mediate $\mathrm{AD}$ associated $A \beta$ aggregation, ROS generation, and oxidative stress in addition to addressing metal dysregulation [50].

Such studies have been successfully carried out on several platinum complexes. It was also found that the complex of imidazole and ruthenium showed greater toxicity than that of imidazole and platinum (the toxicity of ruthenium compounds was lower than that of platinum). Complex 95, formed by $\mathrm{RuCl}_{2}$ and thiazole, can also treat $\mathrm{AD}$ by forming an adduct with $\beta$-amyloid and scavenging $\beta$-amyloid.

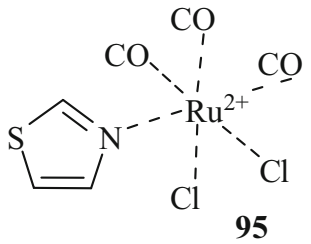

Buserelin acetate, an artificial synthetic nonapeptide, could form an inclusion complex with DM- $\beta-C D$. Ultraviolet absorption and circular dichroism (CD) spectroscopies indicated that the aromatic rings in side chain residues of L-tryptophan and L-tyrosine and the butyl group in serine were incorporated into the hydrophobic cavity of DM- $\beta-C D$, and resulted in space conformational change of the peptide chain, prevented unstable sites from being attacked by protease, and thereby enhanced the stability of buserelin [36]. Flutamide (FLT) is a nonsteroidal antiandrogen, and the formed FLT-HP- $\beta$-CD complex could improve oral bioavailability relative to FLT suspension. Intravenous pharmacokinetic profiles for both FLT and FLT-HP- $\beta$-CD were identical. The effect of HP- $\beta-C D$ on the bioavailability of hydrocortisone (HC) as ophthalmology administration was investigated in the New Zealand rabbit, and HP- $\beta$-CD was found to increase the bioavailability of $\mathrm{HC}$ in the cornea by $75 \%$ and greatly enhance the permeability of the cornea.

\section{Conclusions and Outlook}

The foregoing discussion shows that supermolecules as medicinal drugs formed by two or more molecules through the weak interactions of noncovalent bonds, such as coordination bonds, hydrogen bonds, ion-dipole cation- $\pi, \pi-\pi$ stacking, hydrophobic effect, and van der Waals forces, have been a quite rapidly developing, increasingly active, and newly rising interdisciplinary focus. Supramolecular drugs have shown positive roles in many medicinal aspects such as antitumor, antiinflammatory, analgesic, antimalarial, antibacterial, antifungal, antivirus, antiepileptic, cardiovascular agents, and magnetic resonance imaging agents. In particular, many supramolecular drugs such as antitumor, antiinflammatory, and magnetic resonance imaging agents have been extensively used in clinics and brought benefits to human health. 
The supramolecular drugs might effectively enhance stability and safety, decrease toxicity, eliminate abnormal flavor, overcome multidrug resistance, reduce adverse effects, and improve drug targeting, biocompatibility, and bioavailability. All these excellent properties could improve greatly the therapeutic efficacy of drugs. More important is that numerous supermolecules as clinical candidates are in actively ongoing research and development, and supermolecules as medicinal drugs have been shown to possess enormous potential. In addition, supramolecular drugs might require less expense, take shorter time in action, and have greater possibilities as clinical drugs. These virtues have strongly encouraged numerous researchers to engage in the research and development of novel supramolecular drugs. There is no doubt that in future, the research and development of supermolecules as medicinal drugs will become more and more active.

Currently, much important progress has been made in the research of supermolecules as chemical drugs. The hosts of supramolecular drugs were involved in cyclodextrins, porphyrins, polymers, and some other structural compounds, and the guests themselves were drugs or non-drug molecules, but major research in this field focused on the cyclodextrin, porphyrin, and metal complexes. Thus, it should be fairly said that the research of supramolecular drugs is still in the initial stage. With the further expansion of supramolecular chemistry and the deep investigation of the supramolecular drugs, the research and development to access supermolecules as medicinal drugs will continue to be a hot topic and will become more and more active. The main aspects for research in the future might include the following 10 topics:

1. Continuous effort toward clinical drugs as guests to prepare supramolecular medicinal drugs with an attempt to obtain better drugs, especially those with good bioavailability, biocompatibility, and drug targeting, no obvious multidrug resistance, low toxicity, less adverse effect, and good curative effects as well as safety.

2. More work employing nondrug molecules as guests with the hope to discover new supramolecular medicinal drugs, especially those with a novel mechanism of action.

3. Important research to find low-toxicity components of supramolecular medicinal drugs.

4. More exploration to seek low-toxicity hosts to form supramolecular medicinal drugs.

5. Active topic to use metal ions to produce supramolecular medicinal drugs.

6. Studies toward drugability such as bioavailability, biocompatibility, multidrug resistances, low toxicity, adverse effects, and curative effects and safety.

7. Discovery of a novel unique mechanism of action for supramolecular medicinal drugs.

8. Development of highly drug-loaded hosts able to load more drugs and the study of these hosts as drug carriers.

9. Evaluation of the physicochemical properties of supramolecular medicinal drugs, such as solubility, stability, drug dissolution, and selectivity.

10. Investigation to identify the action targets of supramolecular medicinal drugs. 
Supramolecular drugs are a very rich field of research topics. To some extent, their research is just beginning, and much more work is needed. It is inevitable that more and more workers will engage in the research and development of supermolecules as medicinal drugs. More and more supramolecular medicinal drugs with good efficacy, low toxicity, and good pharmacokinetics properties will then enter into clinical use to serve human health.

\section{Cross-References}

Application of Anion-Pi Interaction on Supramolecular Self-Assembly

- Cyclodextrin Hybrid Inorganic Nanocomposites for Molecular Recognition, Selective Adsorption and Drug Delivery

- Functionalized Cyclodextrins and Their Applications

- Macrocyclic Amphiphiles for Nanomedicine

- Modified Cucurbiturils with Various Ring Size: Functions

Preparation of Biosensor Based on Supermolecular Recognizaiton

- Stimuli Responsive Self-Assembly Based on Macrocyclic Hosts and Biomedical Applications

\section{References}

1. Lehn JM, Atwood JL, Davies LED, MacNIcol DD, Vögtle F (1996) Comprehensive supramolecular chemistry, vols 1-11. Pergamon, New York

2. Liu Y, You CC, Zhang HY (2001) Supramolecular chemistry-molecular recognition and assembly of synthesized receptors. Nankai University Press, Tianjin. (in Chinese)

3. Kimoon K, James M, Narayanan S, Ho KY, Ilha H (2018) Cucurbiturils: chemistry, supramolecular chemistry and applications. University College, London

4. Jayawickramarajah J, Wilson AJ (2017) Comprehensive supramolecular chemistry II: volume 4, bioinspired and biomimetic supramolecular chemistry. Elsevier, Amsterdam

5. Zhang DW, Zhao X, Li ZT (2014) Aromatic amide and hydrazide foldamer-based responsive host-guest systems. Acc Chem Res 47:1961-1970

6. Yu G, Jie K, Huang F (2015) Supramolecular amphiphiles based on host-guest molecular recognition motifs. Chem Rev 115:7240-7303

7. Zhang YM, Liu YH, Liu Y (2019) Cyclodextrin-based multistimuli-responsive supramolecular assemblies and their biological functions. Adv Mater 1806158

8. Zhou J, Yu G, Huang F (2017) Supramolecular chemotherapy based on host-guest molecular recognition: a novel strategy in the battle against cancer with a bright future. Chem Soc Rev 46:7021-7053

9. Zhang J, Meng XG, Zeng XC, Yu XQ (2009) Metallomicellar supramolecular systems and their applications in catalytic reactions. Coord Chem Rev 253:2166-2177

10. Tian J, Zhou TY, Zhang SC, Aloni S, Altoe MV, Xie SH, Wang H, Zhang DW, Zhao X, Liu Y, Li ZT (2016) Three-dimensional periodic supramolecular organic framework ion sponge in water and microcrystals. Nat Commun 7:11464-11467

11. Wang S, Gao W, Hu XY, Shen YZ, Wang L (2019) Supramolecular strategy for smart windows. Chem Commun 55(29):4137-4149

12. Kang X, Zhu M (2019) Intra-cluster growth meets inter-cluster assembly: the molecular and supramolecular chemistry of atomically precise nanoclusters. Coord Chem Rev 394:1-38 
13. Zhou CH, Zhang FF, Gan LL, Zhang YY, Geng RX (2009) Research in supramolecular chemical drugs. Sci China Ser B 39:208-252. (in Chinese)

14. Zhou CH, Gan LL, Zhang YY, Zhang FF, Wang GZ, Jin L, Geng RX (2009) Review on supermolecules as chemical drugs. Sci China Ser B 52:415-458

15. Cheng HB, Cui Y, Wang R, Kwon N, Yoon J (2019) The development of light-responsive, organic dye based, supramolecular nanosystems for enhanced anticancer therapy. Coord Chem Rev 392:237-254

16. Yang Y, Zhang YM, Chen Y, Chen JT, Liu Y (2013) Targeted polysaccharide nanoparticle for adamplatin prodrug delivery. J Med Chem 56:9725-9736

17. Yu QL, Zhang YM, Liu YH, Xun X, Liu Y (2018) Magnetism and photo dual-controlled supramolecular assembly for suppression of tumor invasion and metastasis. Sci Adv 4:2297-2308

18. Xue SS, Tan CP, Chen MH, Cao JJ, Zhang DY, Ye RR, Ji LN, Mao ZW (2017) Tumor-targeted supramolecular nanoparticles self-assembled from a ruthenium- $\beta$-cyclodextrin complex and an adamantane-functionalized peptide. Chem Commun 53:842-845

19. Fu HG, Chen Y, Yu QL, Liu Y (2019) A tumor-targeting Ru/polysaccharide/protein supramolecular assembly with high photodynamic therapy ability. Chem Commun 55:3148-3151

20. Singh S, Aggarwal A, Bhupathiraju NVSDK, Arianna G, Tiwari K, Drain CM (2015) Glycosylated porphyrins, phthalocyanines, and other porphyrinoids for diagnostics and therapeutics. Chem Rev 115:10261-10306

21. Subhendu KD, Arijit G, Srijita PC, Nyancy H, Ishita R, Souvik S, Krushna CS, Harapriya R, Benu BD (2018) Neutral porphyrin derivative exerts anticancer activity by targeting cellular topoisomerase I (Top1) and promotes apoptotic cell death without stabilizing Top1-DNA cleavage complexes. J Med Chem 61:804-817

22. Hu D, Liu YG, Lai YT, Tong KC, Fung YM, Lok CN, Che CM (2016) Anticancer gold (III) porphyrins target mitochondrial chaperone Hsp60. Angew Chem Int Ed 55:1387-1391

23. Lam TL, Tong KC, Yang C, Kwong WL, Guan XG, Li MD, Lo VKY, Chan SLF, Phillips DL, Lok CN, Che CM (2019) Luminescent ruffled iridium (III) porphyrin complexes containing Nheterocyclic carbine ligands: structures, spectroscopies and potent antitumor activities under dark and light irradiation conditions. Chem Sci 10:293-309

24. Mitra K, Basu U, Khan I, Maity B, Kondaiah P, Chakravarty AR (2014) Remarkable anticancer activity of ferrocenyl-terpyridine platinum (II) complexes in visible light with low dark toxicity. Dalton Trans 43:751-763

25. Poulomi S, Sudipta B, Shivani S, Ambarish P, Bhaskar R, Michael SO, Kenneth TC, Abhimanyu SP, Sasmit S, Yamicia C, Venkata SS, Jawahar K, Ashish K, Katherine M, Chitra A, Innocent J, Nicola L, Daniela MD, Bonventre JV, Mashelkar RA, Sengupta S (2012) Cholesterol-tethered platinum II-based supramolecular nanoparticle increases antitumor efficacy and reduces nephrotoxicity. PNAS 28:11294-11299

26. Yu GC, Zhang MM, Saha ML, Mao ZW, Chen J, Yao Y, Zhou ZJ, Liu YJ, Gao CY, Huang FH, Chen XY, Stang PJ (2017) Antitumor activity of a unique polymer that incorporates a fluorescent self-assembled metallacycle. J Am Chem Soc 139:15940-15949

27. Zhang W, Li Y, Sun JH, Tan CP, Ji LN, Mao ZW (2015) Supramolecular self-assembled nanoparticles for chemo-photodynamic dual therapy against cisplatin resistant cancer cells. Chem Commun 51:1807-1810

28. Wei T, Chen C, Liu J, Liu C, Posocco P, Liu XX, Cheng Q, Huo SD, Liang ZC, Fermeglia M, Pricl S, Liang XJ, Rocchi P, Peng L (2015) Anticancer drug nanomicelles formed by selfassembling amphiphilic dendrimer to combat cancer drug resistance. PNAS 10:2978-2983

29. Sarkar K, Khasimbi S, Mandal S, Dastidar P (2018) Rationally developed metallogelators derived from pyridyl derivatives of NSAIDs displaying anti-inflammatory and anticancer activities. ACS Appl Mater Interfaces 10:30649-30661

30. Freitas CS, Roveda AC, Truzzi JR, Garcia DR, Cunha AC, Cunha TM, Franco FQ (2015) Antiinflammatory and anti-nociceptive activity of ruthenium complexes with isonicotinic and nicotinic acids (niacin) as ligands. J Med Chem 58:4439-4448 
31. Zhong HJ, Wang W, Kang TS, Yan H, Yang Y, Xu L, Wang Y, Ma DL, Leung CH (2017) A rhodium(III) complex as an inhibitor of neural precursor cell expressed, developmentally downregulated 8 -activating enzyme with in vivo activity against inflammatory bowel disease. J Med Chem 60:497-503

32. Markwalter CF, Kantor AG, Moore C, Richardson KA, Wright DW (2019) Inorganic complexes and metal-based nanomaterials for infectious disease diagnostics. Chem Rev 119:1456-1518

33. Schattschneider C, Doniz Kettenmann S, Hinojosa S, Heinrich J, Kulak N (2019) Biological activity of amphiphilic metal complexes. Coord Chem Rev 385:191-207

34. Ohui K, Afanasenko E, Bacher F, Ting RLX, Zafar A, Blanco-Cabra N, Torrents E, Domotor O, May NV, Darvasiova D, Enyedy EA, Popovic-Bijelic A, Reynisson J, Rapta P, Babak MV, Pastorin G, Arion VB (2019) New water-soluble copper(II) complexes with morpholinethiosemicarbazone hybrids: insights into the anticancer and antibacterial mode of action. J Med Chem 62:512-530

35. Li S, Chen JX, Xiang QX, Zhang LQ, Zhou CH, Xie JQ, Yu L, Li FZ (2014) The synthesis and activities of novel mononuclear or dinuclear cyclen complexes bearing azole pendants as antibacterial and antifungal agents. Eur J Med Chem 84:677-686

36. Samanta T, Roymahapatra G, Porto WF, Seth S, Ghorai S, Saha S, Sengupta J, Franco OL, Dinda J, Mandal SM (2013) $N, N^{\prime}$-Olefin functionalized bis-imidazolium gold(I) salt is an efficient candidate to control keratitis-associated eye infection. PLoS One 8:58346-28358

37. Ruan BF, Zhu YZ, Liu WD, Song BA, Tian YP (2014) Synthesis, characterization, cytotoxicity and antibacterial activity of an anthracenyl-linked bis(pyrazolyl)methane ligand and its zinc(II) complexes. Eur J Med Chem 72:46-51

38. Sulpizio C, Breibeck J, Rompel A (2018) Recent progress in synthesis and characterization of metal chalcone complexes and their potential as bioactive agents. Coord Chem Rev 374:497-524

39. Savić ND, Vojnovic S, Glišić BĐ, Crochet A, Pavic A, Janjić GV, Pekmezović M, Opsenica IM, Fromm KM, Nikodinovic-Runic J, Djuran MI (2018) Mononuclear silver(I) complexes with 1,7-phenanthroline as potent inhibitors of Candida growth. Eur J Med Chem 156:760-773

40. Zheng BY, Ke MR, Lan WL, Guo J, Wan DH, Chong LZ, Huang JD (2016) Mono- and tetrasubstituted zinc(II) phthalocyanines containing morpholinyl moieties: synthesis, antifungal photodynamic activities, and structure-activity relationships. Eur J Med Chem 114:380-389

41. Chen F, Moat J, McFeely D, Clarkson G, Hands-Portman IJ, Furner-Pardoe JP, Harrison F, Dowson CG, Sadler PJ (2018) Biguanide iridium(III) complexes with potent antimicrobial activity. J Med Chem 61:7330-7344

42. Hamal S, Thomas D, Rowley WF, Vermeire K, Aquaro S, Frost BJ, Dominique S, Thomas WB (2015) Metal complexes of pyridine-fused macrocyclic polyamines targeting the chemokine receptor CXCR4. Org Biomol Chem 13:10517-10526

43. Brooks WLA, Sumerlin BS (2016) Synthesis and applications of boronic acid-containing polymers: from materials to medicine. Chem Rev 116:1375-1397

44. Zuo MZ, Qian WR, Xu ZQ, Shao W, Hu XY, Jiang JL, Wang LY, Hu XY, Zhang DG, Sun XQ, Wang LY (2018) Multiresponsive supramolecular theranostic nanoplatform based on pillar [5] arene and diphenylboronic acid derivatives for integrated glucose sensing and insulin delivery. SMALL 14:e1801942

45. Chen G, Li JL, Song MC, Wu ZY, Zhang WZ, Wang ZY, Gao J, Yang ZM, Ou CW (2017) A mixed component supramolecular hydrogel to improve mice cardiac function and alleviate ventricular remodeling after acute myocardial infarction. Adv Funct Mater 27:1701798

46. Li H, Gao J, Shang YN, Hua YQ, Ye M, Yang ZM, Ou CW, Chen MS (2018) Folic acid derived hydrogel enhances the survival and promotes therapeutic efficacy of iPS cells for acute myocardial infarction. ACS Appl Mater Interfaces 10:24459-24468

47. Xu G, Lv B, Roberge JY, Xu B, Du J, Dong J, Chen Y, Peng K, Zhang L, Tang X, Feng Y, Xu M, Fu W, Zhang W, Zhu L, Deng Z, Sheng Z, Welihinda A, Sun X (2014) Design, synthesis, and biological evaluation of deuterated $\mathrm{C}$-aryl glycoside as a potent and long-acting renal 
sodium-dependent glucose cotransporter 2 inhibitor for the treatment of type 2 diabetes. J Med Chem 57:1236-1251

48. Ko CN, Li GD, Leung CH, Ma DL (2019) Dual function luminescent transition metal complexes for cancer theranostics: the combination of diagnosis and therapy. Coord Chem Rev 381:79-103

49. Willsky GR, Chi LH, Iii MG, Kostyniak PJ, Smee JJ, Trujillo AM, Alfano JA, Ding W, Hu Z, Crans DC (2011) Anti-diabetic effects of a series of vanadium dipicolinate complexes in rats with streptozotocin-induced diabetes. Coord Chem Rev 255:2258-2269

50. Robert A, Liu Y, Nguyen M, Meunier B (2015) Regulation of copper and iron homeostasis by metal chelators: a possible chemotherapy for Alzheimer's disease. ACC Chem Res 48:1332-1339 